\title{
A Semiotic Modern Synthesis: Conducting Quantitative Studies in Zoosemiotics and Interpreting Existing Ethological Studies through a Semiotic Framework
}

\author{
Amelia Lewis ${ }^{1}$ (D) \\ Received: 7 December 2020 / Accepted: 7 June 2021/ Published online: 20 July 2021 \\ (C) The Author(s) 2021
}

\begin{abstract}
In this paper, I present an argument that quantitative behavioural analysis can be used in zoosemiotic studies to advance the field of biosemiotics. The premise is that signs and signals form patterns in space and time, which can be measured and analysed mathematically. Whole organism sign processing is an important component of the semiosphere, with individual organisms in their Umwelten deriving signs from, and contributing to, the semiosphere, and vice versa. Moreover, there is a wealth of data available in the traditional ethology literature which can be reinterpreted semiotically and drawn together to make a cohesive biosemiotic whole. For example, isolated signals, such as structural elements of birdsong, are attributed meaning by an interpreter, thus generating new ideas and hypotheses in both biology and semiotics. Furthermore, animal behaviour science has developed numerous test paradigms that with careful adaptation, could be suitable for use within a Peircean tripartite model, and thus give valuable insights into Umwelten of other species. In my conclusion, I suggest that by bringing together traditional ethology and biosemiotics, it is possible to use the Modern Synthesis to provide context to biosemiosis, thus pragmatic meaning to animal signals. On this basis, I propose updating the Modern Synthesis to a Semiotic Modern Synthesis, which focuses on whole-organism signals and their contexts, the latter being derived from neo-Darwinian theory and the 'Umwelt'. Thus, there need be no dichotomy; the Modern Synthesis can successfully be integrated with biosemiotics.
\end{abstract}

Keywords Zoosemiotics · Ethology · Evolutionary biology · Animal behaviour · Extended Synthesis · Quantitative methodology · Umwelt · Peircean tripartite model · Animal welfare

Amelia Lewis

alewis08@qub.ac.uk

1 School of Biological Sciences, Queen's University, Belfast, UK 


\section{Introduction}

In recent years, evidence for an updated Modern Synthesis, in the form of an 'Extended Synthesis' has mounted (Noble, 2021), and Evolutionary and Developmental Biology (Evo-Devo) is a growing field which focusses on the influence of the environment on embryonic development and the genome (Hall, 2012). However, the focus to date has been on epigenetics and cellular physiology (Ashe et al., 2021). The aim of this paper is therefore to include ethology and behavioural ecology by bringing together von Uexküll's 'Umwelt Theory' and Peirce's tripartite semiotic model with the Modern Synthesis. To achieve this, existing quantitative scientific methodologies in both ethology and animal welfare can be developed, and biosemiotic frameworks can be used to answer Tinbergen's 'Four Questions'(Tinbergen, 1963) which provide a key framework in ethology. However, Tinbergen's questions can be answered from Thomas Sebeok's zoosemiotic perspective by using Peircean semiotics is an intermediary tool to explore the Umwelten and Innenwelten of other species, which in turn provide the context in which behaviours take place. I also suggest using existing peer- reviewed data from the neo-Darwinian literature as a basis for zoosemiotic studies, as a wealth of data exists which can be assembled to explore the 'meaning' signs and social signals for other species.

This essay by no means implies that quantitative data should replace qualitative data; indeed, quantitative studies in ethology rely on qualitative assessments of animal behaviour. Nonetheless, quantitative data analysis reveals patterns in physical relations between objects in space and time, in movement, in energetic waveforms and, indeed, in the whole of the living and physical world. Significantly, the very semiosphere we inhabit consists of patterned signals (Lewis, 2020a), be they in the form of energy (such as acoustic or photic waveforms), tactile mechanical waveforms (pressures and forces), or matter (such as diffused odour molecules). The premise of my argument is therefore that quantitative data, when integrated with qualitative analyses to give the data meaning, provides a comprehensive approach to studying animal behaviour. Therefore, Umwelt Theory forms the basis for the Modern Synthesis, which becomes a contextual framework in which signs and social signals are the focus of processes driving 'natural selection'. To some degree those signs and signals come under control of the individual organism (or 'agent') as well as environmental selection pressures, and a 'Semiotic Modern Synthesis' takes shape.

However, it is important to emphasize that the biosemiotic criticism of the Modern Synthesis has, to date, focussed on genotype. At a whole organism level, though, the focus is on phenotype (including behavioural traits) and an organism's 'Lifetime Reproductive Success'. The latter is a trade-off between survival and reproduction and relies upon an individual maximising its resource allocation between the two (McLoughlin et al., 2006). Behaviourally, this can be summarized as avoidance of predators, disease, injury, and starvation, and concurrently, attraction to potential mates, food sources, suitable environmental conditions (e.g., temperature/humidity/ $\mathrm{pH}$ ), shelter, and in sociable species, social groups. Concisely summarized, these behaviours are 'approach/ avoid' and 'synergism' and 'antagonism', the latter usually referred to as 'co-operation and conflict', respectively.

In their most basic form, these binary phenomena can be observed during bacterial chemotaxis and gradient descent searches (Dasgupta et al., 2008; Salek et al., 2019). Significantly, though, when the speed of this binary process is increased in 
multicellular animals (i.e., during the processing of sensory data), an emergent property is likely to be complex pattern recognition. Indeed, Salek et al. (2019) observed different strategies within individuals in their experimental population of bacterial cells, some tending toward exploration of the chemical landscape; others tending toward chemotaxis. This suggests that a trait analogous to 'personality' in higher organisms occurs even in bacteria, where choices are based on chemical sensitivity and simple feedback loops. Moreover, such feedback loops, which form simple patterns, can be found in plants as well as animals. I therefore argue they laid the foundation for the evolution of increasingly complex pattern recognition, within the constraints of the Umwelt, ultimately giving rise to consciousness.

A combined approach to studying ethology and quantitative biosemiotics would therefore be beneficial across the biological sciences. For example, it could be used to study and perhaps explain sympatric speciation events. During sympatric speciation, mating signals and their meaning change over evolutionary time and eventually, in geographical space; yet the meaning of signals change for some, but not all individuals in a population. This indicates that those individuals have agency, and mating signals have meaning beyond being simple 'stimuli'. Perhaps the explanation is that they are iconic signs, related to resources in a patchy habitat, as discussed in Lewis (2020a).

Moreover, when considering phenomena such as intralocus sexual conflict, where neo-Darwinian theories consider an allele as being of 'fitness' benefit to one sex but detrimental to the other (Wright et al., 2019), it may be that the perceived 'conflict' does not occur. Thus, various explanations for such apparent conflicts at a genetic and population level are not relevant in organisms who are interpreting signs and signals in ways which have relevant meaning to them as holistic individuals. For example, a brightly coloured female lizard or bird, of a dichromatic species with no sexual dimorphism, may be no more 'attractive' to a male than a dull coloured female. However, traditional neo-Darwinism considers her at a disadvantage because she is more conspicuous to predators, with no reproductive advantage. Nonetheless, if she is more conspicuous to predators, then there must still be something about her as a 'sign' which suggests she is food before she is attacked. Colour alone is not sufficient, and further, her vulnerability also relies on the assumption that a predatory species has a similar capacity to detect those colours as a potential mate. Thus, a female is not necessarily at any significant disadvantage compared to a male because her agency (her ability to interact with the environment) means she is not simply at the whim of her environment. She has the options to detect and take cover from predators or to freeze, both of which alter her sign to a predator. She might make herself conspicuous to males, increasing her probability of encountering a mating opportunity, and her colouring will likely have some significance to a potential mate, even if only to allow him to identify her as the same species. Nonetheless, in a biological sense, her 'agency' is not necessarily the same as the sociological and psychological definitions, which are subjective, according to human experience. Rather, her agency relies on the ability to interpret, manipulate, and produce complex signals.

Thus, I suggest a quantitative definition of 'agency' for the purposes of biosemiotic ethological study is:

'An individual's ability to detect, interpret and transmit patterned signals in space and time, both within the Umwelt and Innenwelt'. 
This means that at a whole organism level, it is patterned signals which are the empirical aspect of the construct called 'agency', and it is patterned signals on which evolutionary processes act. This includes signals in the Innenwelt, such as the complex patterns of neurological firing and endocrine signals which produce emotions, homeostatic mechanisms, memories, and complex feelings such as guilt and shame.

Thus, whilst biosemiotics is a field which has developed independently of classical biology and the Modern Synthesis, traditional ethology is still valid and can provide invaluable quantitative data. Indeed, it would be short-sighted to disregard the fact that evolution is a multi-layered phenomenon; at its most fundamental level, genetic variation in a population means that there are individuals who have phenotypic traits. Certain variations of those traits mean some individuals can interact with the environment more successfully than others who do not share those traits. Statistically, some individuals are therefore more likely to pass on advantageous heritable traits than others. Some cellular traits may be acquired (Noble, 2021) yet many are coded in the genome and are reflected in the phenotype. However, I argue that it is the phenotype as a complex pattern which is acted upon by 'selection'.

Therefore, the environment, or Umwelt, is a real phenomenon which makes environmental determinism part of the complex dynamic processes within in the living domain. Like Classical Mechanics in physics, where forces act on matter, selection does 'act' on organisms, and it is indiscriminate. Individual 'agency' does not always succeed in a universe tending toward entropy; nor does population- level agency (defined as the mathematical sum of those complex processes which confer agency in the population's individuals). Indeed, it is generally accepted that there have been five mass extinction events during the known history of life on Earth (Whiteside \& Grice, 2016). However, agency is a factor, amongst many other variables, which contributes to a complex dynamic biological system. Nonetheless, other variables include deterministic factors, autonomy, and random chance. It is therefore possible for an integration of traditional methodologies and biosemiotics, and inclusion of biosemiotic ideas in the classical biological sciences, and vice versa.

However, this article is not a complete and definitive proposal of how ethological studies could be conducted using biosemiotic frameworks; rather, it is an exploration of the possible avenues open to biosemioticians and biologists. I thus propose a solution to the current dichotomy between biosemiotic theories of evolution and the Modern Synthesis, by demonstrating that they do not need to be mutually exclusive. In fact, the Modern Synthesis is still relevant, not least because organisms will be encountering the agency of other organisms in their Umwelt, such is the nature of 'competition' and 'co-operation'. Indeed, the life of an individual with agency is like a chess tournament; an agent has an environment of limited dimensions, in which its movements are restricted according to anatomy and physiology. It has limited resources at its disposal, and it is facing other players of both known, and unknown variables. It has control over how it plays, within those parameters.

In this analogy (and in my definition of 'agency') there are striking similarities with machine learning and AI, which is unsurprising given that software programmers are humans, thus living biological agents. However, being an organic living organism is a unique experience. Computers can be programmed to interpret biologically relevant signs and signals through an approximation of human sensory perception, but it is unlikely they will ever experience the nuances of being organic and alive. To illustrate, 
I will return to the chess tournament analogy. In 1997, when IBM's supercomputer, 'Deep Blue', beat chess Grandmaster Garry Ksaparov, Kasporov was able to experience and then communicate to his conspecifics, what his loss felt like and what it meant to him. 'Deep Blue', however, has been notably silent with respect its victory; an unfair victory, perhaps? Throughout the tournament, Kasparov was perceiving trillions of patterned signs and signals, from sensory perceptions, emotions such as anxiety, and physiological sensations such as hunger, to the cultural and social norms of being in a social setting. Meanwhile, 'Deep Blue' was able to concentrate solely on its game. Thus, complex pattern recognition in living organisms will always be subtly different from machines, however advanced the technology becomes.

\section{Adapting Quantitative Experimental Paradigms for Biosemiotic Studies}

There are three paradigms which are key in moving forward with a semiotic modern synthesis. These are:

1. Peircean Semiotics

2. Umwelt Theory

3. Tinbergen's 'Four Questions' on the proximate and ultimate causes of a behaviour. These ask questions about:
i. Causation
ii. Survival value
iii. Ontogeny
iv. Evolution

Each question 'interrogates' an observed behaviour to glean information about the animal, by examining its proximate (mechanistic/physiological and developmental) causes ('how' questions), and ultimate (evolutionary and adaptive) causes (why questions). Before planning or beginning any ethological study, a research question must be posed, and Tinbergen's Four Questions provide the framework for that question. However, by answering research questions using the proposed biosemiotic model, signs and signals are emphasized, thus allowing for individual agency, whereas the Modern Synthesis focusses on coarse environmental 'selection pressures', which are still relevant when treated synergistically.

The tripartite Peircean model is the tool by which this perspective can be achieved. However, this involves employing not only a novel interpretation of Tinbergen's methods for studying animal behaviour, but also a novel interpretation of Peircean semiotics. The resulting framework treats constructs, such as emotions and animal signals, as 'objects' or 'referents' from the point of view of the researcher. However, it does not assume an organism has unfettered agency; the organism's interactions with its physical and social environment are dynamic and using Newton's Laws of Motion as an analogy, the environment reacts when an organism acts, even if only at a molecular level. Indeed, how else would tactile senses work if it were not for equal and opposite reactions?

The two current dominating theories in ethology are Behaviourism and Behavioural Ecology. Behaviourist theories, where animals interact with their world and learn about 
it via 'reinforcement' and 'punishment' learning, analogously view the environment as writing a software program for an individual, whose physical body is a 'hardware user interface'. Meanwhile, behavioural ecologists treat animals as having intrinsic behaviours encoded in their DNA, such as 'Modal Action Patterns' (previously known as 'Fixed Action Patterns') which are used to interact with the environment; they rely on the environment to be a 'software program user'. The proposed semiotic framework recognizes both schools of theory, but combines them with semiotics and 'agency'- or the production and recognition of complex patterns. To elucidate:

- Tinbergen's Four Questions allow researchers to isolate what aspect of the behaviour is being interrogated by the study i.e., is it the adaptive value, the mechanism, a developmental trait, or a phylogenetic aspect?

- Umwelt theory, with the 'Umwelt' being defined as the perceived and interactive physical environment external to the organism's boundary, and the Innenwelt being internal homeostatic, affective, cognitive, and physiological processes within its boundary. This is the framework in which the Modern Synthesis exists, and produces patterned signals which must be interpreted by agents, and is also the vehicle by which patterned signals can be transmitted by agents.

- Peircean semiotics defines what would currently be termed the 'stimulus' and 'response'. However, the behaviour is not as merely interpreted as a response to a stimulus (neither treating the animal as hardware for which software can be programmed, nor a software program with a user interface, where the environment is the 'user'). Instead, the organism is an interpreter, not simply a 'receiver' of a signal. The tripartite model also gives scope for study of the patterned signs and signals, in the form of electro-magnetic radiation, mechanistic vibrations, and shapes and/or vibrational frequencies of volatile odorant molecules. This includes the patterned physiological and neurological effects of those sensory phenomena; thus, the Innenwelt. Indeed, the Peircean tripartite model can be translated into an algebraic function, which represents the conversion of patterned signs of energetic waveforms and matter, to complex patterned neurological signals. In simple organisms without a nervous system, however, those patterns are made up of positive or negative feedback loops. Nonetheless, with time as the dependent variable, such simple feedback loops also form patterned signals, albeit much less complex.

Thus, here I present a selection of quantitative methodologies to give examples of the various tools which are available to biosemioticians studying animal behaviour. All methodologies described rely on experimental or observational data collection, followed by mathematical analysis of the data. Quantitative analyses usually involve performing appropriate statistical tests and/or mathematical modelling, which I will not cover in detail in this paper. However, there are many resources available which describe and discuss statistics in the biological sciences, such as Beckerman et al. (2017) and (Dytham, 2011), and further resources are listed in the appendix.

It is important to emphasize that the design of any study is key in minimising confounding variables, avoiding pseudo- replication and ensuring that the sample size is large enough to give the study sufficient statistical power. A well-designed study, with a clearly defined hypothesis and research question, followed by the appropriate statistical analysis, ensures that the results will be as reliable as is possible (Lehner, 
1987). The listed techniques in this section are validated methodologies which are adaptable for semiotic studies. Indeed, quantitative linguistic techniques are already employed to study animal communication and cognition (Favaro et al., 2020; Malassis et al., 2018) and thus, development and adaptation of the suggested paradigms is eminently possible.

\section{a) Behavioural Sampling and Coding}

Behavioural sampling is a quantitative method of studying ethology and relies on defining and then observing an animal's behaviours during a given period, with a record being made of measurements of the variables. Measurements recorded include:-

i) Behavioural states; continuous, uninterrupted behaviours, such as walking, running/trotting/galloping, flying, swimming, sleeping, lying down, singing.

ii) Behavioural events: a single occurrence of a behaviour, such as a short vocal call, kick, bite, yawn, paw-raise, nose-nudge. There is overlap with behavioural states, e.g., the act of lying down would be an event, whilst the continued behaviour would be a state.

iii) Behavioural bouts: a sequence of one or more specified behaviours occurring with contiguity, but which are shorter in duration than a behavioural state. Examples include some stereotypic behaviours such as 'weaving' in horses, allogrooming, and play.

There are different methods of data collection, depending on the hypothesis and design of the study. Examples are summarised as follows:-

- Scan sampling: at timed intervals, a group of animals is scanned to count and record how many individuals are performing a particular behaviour.

- Focal animal sampling: continuous observations of one individual, recording all the behaviours it performs during a specified period.

- Instantaneous sampling: recording the behavioural state of one animal at set intervals.

Behaviours are then 'coded'. Coding involves describing and defining individual behaviours according to a pre-determined ethogram (essentially, a lexicon of signs and signals), and these behavioral definitions are then used to record quantitative measures of behaviour. Data include the frequency with which a behaviour occurs, the duration of a bout or state, the latency for an animal to begin a particular behaviour, or the number of animals in a group performing a behaviour at any one time. This list is not exhaustive, but from the original count data, ratios and proportions can also be calculated. Coding can be done 'by eye' in the field, or from audio-visual recordings. The benefit of the latter is that data can be gathered over long periods (e.g., over- night) whilst the researcher is absent, and can be coded with the aid of computer software such as 'Solomon Coder'.

For more detail on behaviour sampling and recording methodologies and paradigms, and for further information, Martin et al. (1993) is established as a standard text, and is the reference for the described methodologies in this essay. However, there are many 
books on the subject, including one focussing specifically on observational rather than experimental studies, by Dawkins (2007).

In adapting these methodologies in a Peircean framework, the recorded behavioural data is reinterpreted as being a series of signs, signifying a part of an Umwelt and Innenwelt. The theory behind this, is that the behaviours are indicative of an internal motivational-emotional state. The 'motivational' state was described by Morton, 1977, as part of his Motivational-Structural Rules for animal vocalizations. It is developed further by neuroscientist Jaak Panksepp, as part of his theory of 'Affective Neuroscience', which is described and discussed in the book 'Affective Neuroscience: The Foundations of Human and Animal Emotions' (Panksepp, 2004). The motivational state derives from the Umwelt or Innenwelt, and is mediated by affective (emotional) states. Behaviours are therefore representamen to the observer, the 'referent' being the motivational or affective state of the animal, or the situation in which the animal finds itself. From the animal's perspective, the emotion and/or cognitive processes can therefore be considered a representamen, with the animal being the interpreter, as described in Table 1.

Thus, a complex web of signs is formed, involving the researcher as well as the nonhuman animal subject. Indeed, whilst the tripartite model is usually represented linguistically or graphically, it can also be described as a mathematical function, as demonstrated in Table 2.

To elucidate, the representamen is an argument made up of a patterned sign or, where there is more than one sign, a domain. The signal is perceived and interpreted by the interpreter, as a complex patterned neural signal, and the interpretant is the function output, or 'range', emerging from the function's codomain. Hence, more cognitively complex animals are capable of handling logic, ambiguity, and complexity resulting from domains of patterned signs and signals.

All kinesic behaviours (including both individual and group behaviours, such as shoaling), form patterned signs, which are interpreted by agents to give them meaning. Thus, existing study paradigms which use behavioural signs to represent affective state or cognitive ability would benefit from this model, as I will go on to discuss.

Table 1 Model incorporating Peircean tripartite semiotics into observational and experimental ethological study. Similar tables can be included in research study methodologies, and there can be more than one interpretant. Either alternative or simultaneous interpretants can be proposed

\begin{tabular}{|c|c|c|c|}
\hline Interpreter & Referent & Representamen & Interpretant \\
\hline Animal & $\begin{array}{l}\text { i. Sign in external environment } \\
\text { (Umwelt) e.g., approach of } \\
\text { a fast- moving object } \\
\text { ii. Cue in internal environment } \\
\text { e.g., Low blood sugar } \\
\text { (Innenwelt) }\end{array}$ & $\begin{array}{l}\text { Predator/ Emotion, Fear } \\
\text { Sensation, hunger }\end{array}$ & $\begin{array}{l}\text { Danger/ therefore, 'Run' } \\
\text { Consume food/eat }\end{array}$ \\
\hline Researcher & $\begin{array}{l}\text { Emotion, Fear } \\
\text { Sensation, Hunger }\end{array}$ & $\begin{array}{l}\text { i. Dog moving fast at a running } \\
\text { or galloping gait; eyes wide, } \\
\text { ears laid back, tail tucked. } \\
\text { ii. Bird engaging in } \\
\text { locomotory behaviour, } \\
\text { pecking at the ground; low } \\
\text { glucose levels in blood test }\end{array}$ & $\begin{array}{l}\text { Fearful/ avoidant behavioural } \\
\text { response } \\
\text { Bird experiencing sensation of } \\
\text { hunger }\end{array}$ \\
\hline
\end{tabular}


Table 2 Peircean tripartite model interpreted as a mathematical function

\begin{tabular}{lll}
\hline Referent $\rightarrow$ & Representamen $\rightarrow$ & Interpretant \\
\hline Domain $/$ or argument $\rightarrow$ & Function $\rightarrow$ & Range or Codomain \\
Agent $/$ Signaller $\rightarrow$ & Signal $\rightarrow$ & Interpreter; Sensory Processing \& Cognitive output
\end{tabular}

\section{b) Cognition and Emotion Studies}

Cognition and emotion studies use the described behavioural sampling techniques to attempt to link the outward expression of behaviour to the internal cognitive motivational- emotional states of an animal, or part of the Innenwelt. Cognitive study techniques include assessment of animals' cognitive processes through studies, such as 'Go/No-go' paradigms, discrimination tasks, problem solving and choice modelling. Methods employed in experimental studies include using equipment such as T- mazes, radial arm mazes, water mazes, puzzles and training an animal to perform specific behaviours which indicate a particular choice. Thus, cognitive functions including spatial learning and memory can be assessed (Bird et al., 2003; Nicol, 1996; Shields et al., 2004). Moreover, more recent developments mean that the use of touch- screen technology allows animals to indicate choice by touching an icon on a liquid crystal display screen (Dale et al., 2019).

However, cognition studies are not limited to laboratory settings. Behaviours such as food caching can be studied in wild populations (Dally et al., 2006), thus providing insight into episodic memory as well the ability to plan for the future. Studying tool use in wild populations reveals data related to phenomena such as problem solving, social learning and animal cultures (Emery \& Clayton, 2004), and moreover, mathematical modelling of movement can reveal movement patterns, such as Random Walks and Lévy walks (Auger-Méthé et al., 2015; Codling et al., 2008). Furthermore, empirical data on animal movement can be collected and analysed, using biotelemetry techniques such as data loggers and satellite transmitters (Byrne et al., 2009). The lightweight transmitters are attached directly to the animal without causing any harm, and biotelemetry studies can yield vast amounts of data on migratory species, which navigate globally.

In studies on animal emotion, the concept of emotional 'valence' and emotional arousal are used, as in human psychology. The Innenwelt of another individual, particularly of another species, is difficult to describe; however, these emotional states can be inferred from observed behaviours, using the valence model described in Fig. 1, based upon Mendl et al.'s (2010) model .

This is significant, as identifying emotional valence can elicit the approximate meaning of a sign or social signal. The meaning of the behavioural sign, or how it is interpreted, depends on the context and outcome of the behaviour. This can be problematic when delineating between certain behaviours which share features, such as aggressive behaviour and play, the latter often being difficult to define and interpret, as evidenced by Burghardt's (2014) synopsis of play behaviour across taxa. In the example of play and aggression, interactions between two or more individuals can involve behavioural states and events such as chasing, running, 'rough and tumble', vocalisations, wing flapping in birds, and mouthing in mammals. These behaviours all feature across both motivational and emotional contexts. 


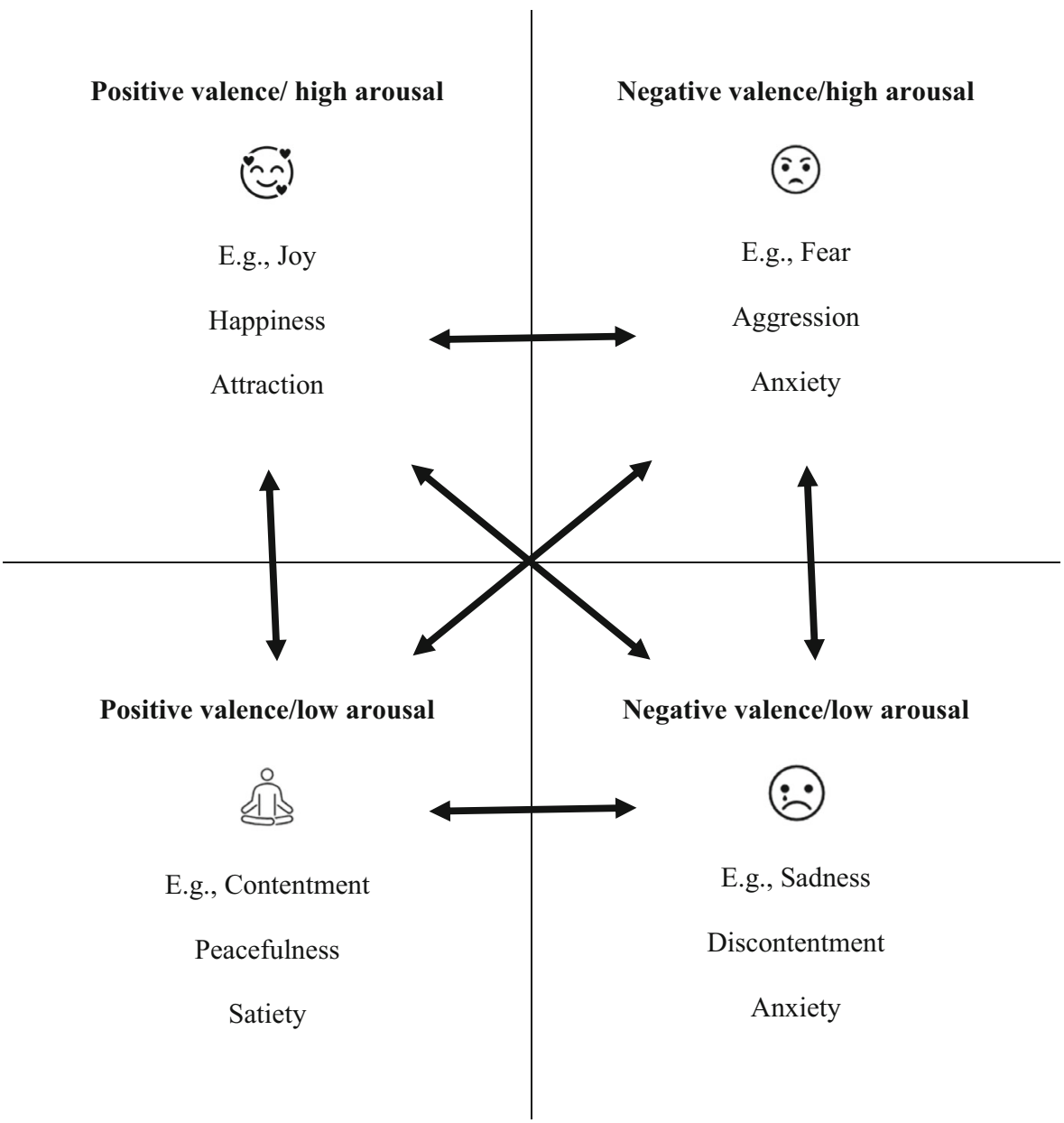

Fig. 1 Model representing emotional valence (positive or negative) and emotional arousal (high or low). This model is a continuum of different emotional states, examples of which are given in each section (based upon Mendl et al., 2010)

Moreover, play behaviour can easily tip into aggressive behaviour given the high arousal levels involved during a bout, and there are also cases of positively- valanced aggression, where an individual derives pleasure from aggressive behaviour; a phenomenon known as 'appetitive aggression' or 'predatory aggression' (Moran et al. 2014). It is, however, possible to analyse other features such as the context in which the behaviour occurs, body posture, facial expression, and the social relationship between the two agents. Thus, observational studies employing Peircean semiotics can be conducted, with some adjustment of the traditional paradigms, where kinesics and acoustical signals are recorded and analysed as representamen, which refer to an emotional or motivational state. Using pattern recognition software, quantitative mathematical descriptions of those representamen can be analysed as mathematical arguments or domains, and subtle nuances in behaviours can be detected. Further, once individual behaviours have been recorded, complex patterns where more than one behaviour is observed at a time can be described mathematically. 
An example of a technique used to study emotion and cognition is the 'Cognitive Bias Test', also known as the 'Judgement Bias Test' (Mendl et al., 2009). Cognitive Bias Tests involve animals responding to ambiguous cues, and the results are interpreted as being indicative of either a positive or negative judgement bias, or 'pessimistic' or 'optimistic' mental states. This technique is often used to test the effect on an animal's mental state in response to environmental factors (or the Umgebung, from the perspective of the researcher) such as enriched or impoverished environments in domestic, agricultural, captive or laboratory animals (Harding et al., 2004). The test has successfully been used in a variety of animal groups including (but not limited to) canids (Burman et al., 2011), poultry (Wichman et al., 2012) and rodents (Burman et al., 2009).

Another interesting paradigm often used in companion animal studies does not rely on the researcher conducting observational or experimental studies. Behavioural questionnaires or assessment scales such as the 'C-BARQ' (Canine Behavioural Assessment and Research Questionnaire) can be answered by the animal's keeper or caregiver, to identify and classify qualitative behavioural traits or behavioural styles in individuals, before using quantitative analyses to interrogate the results (van den Berg et al., 2010). Questionnaires are validated statistically, using statistical tests such as factor analyses (Gerencsér et al., 2018). However, I suggest that the variability and complexity of results of 'assessment scale' studies found in the literature are indicative of the possibility that whilst trends are potentially being identified, the individual traits measured are influenced by many external factors and are subjectively perceived by an observer. Therefore, the potential need for complex pattern analysis and probabilities, rather than established statistical testing, is perhaps worth investigating.

In addition to those discussed here, there are numerous other paradigms (too many to cover in detail), such as the novel object test and the startle test, which specifically aim to investigate an animal's emotional state. These are critically reviewed by Forkman et al. (2007). Furthermore, social emotional phenomena like empathy can be investigated (De Waal et al., 2008) using specifically designed social paradigms and observations of behavioural signs, and such studies can give insights into the social relationships and group behaviour of other species.

From a semiotic perspective, quantitative analysis is beneficial in the process of defining behavioural signs, as it gives a clearly defined set of criteria by which to analyse results. Moreover, mathematical correlations between data sets add a dimension which allows for more reliable discrimination between different motivational and affective states. For example, counter- coding by another observer, and comparing the results statistically, gives a measure of agreement between two or more observers, and can be an indication of the reliability of the results. Furthermore, quantitative methodologies such as those described allow for repeatability, and meta-analyses of data from different studies can also be performed.

Ethologically, by listing a series of processes with respect the animal's behaviour, it is possible to reduce the risks of human misinterpretation and biases. This is already part of ethological study to some degree, but the difference is that the meaning is interpreted semiotically, rather than in relation to neo-Darwinian 'fitness', or, in animal welfare studies, an indication that something (physical or social) within the environment is either positive or negative, or on a scale between the two. Like neo-Darwinian 'fitness', this simplifies a complex, dynamic system as being either positively or 
negatively affected. It also tends to assume a baseline i.e., that welfare (or 'fitness') is already at a pre-determined level before being improved (or changed, in the case of 'fitness'). Using a combination of Umwelt theory and Peircean semiotics, the results become more nuanced and individualised, whilst also considering a non-human animal's effect on its environment — and its effect on the researcher.

The 'world' can thus be viewed from the animal's perspective as an agent, rather than an inanimate object being subject to evolutionary forces, or unidimensional affective states. Indeed, if the referent, representamen and interpretant are tabulated, both from the point of view of the researcher and the animals being studied, a more comprehensive consideration of alternative interpretations of a behaviour and an animal's Umwelt and Innenwelt can be achieved.

To illustrate this point, consider attempts to provide enrichment for captive predatory species in zoos, such as big cat species. These animals are often given environmental enrichments which simulate prey capture; however, conversely, prey species are not given the opportunity to run from a simulated predator attack. Indeed, the problem has become so significant that 'alternative grazing systems' (Furtardo et al., 2021) are being developed for domestic horses, because of problems with weight gain and the associated risk of laminitis. Thus, as a solution, encouraging locomotory behaviour during foraging (and other 'eustressful' activity) is simulated. However, none simulate fleeing from a predator, as humans consider that to be 'poor welfare'. Nonetheless, this is as 'natural' to a prey animal as hunting is to a predator. Indeed, risk is inherent to all living animals, and without the perception of risk, is animal welfare actually being compromised? Many humans certainly enjoy risk taking and derive excitement from 'extreme sports' and fairground/themepark rides. To summarize this point, 'controlled deprivation' (Burghardt 1999) means that assumptions made in animal welfare are often to varying degrees subjective in nature, imposing our view of what should constitute good welfare, even when we attempt to mimic 'natural' environmental conditions.

The proposed model therefore allows for the observer's interpretations to be summarized and analysed alongside that of the animal's behavioural data. In essence, a 'dictionary' or lexigram can be compiled, based on standard human responses across studies as well as the behaviours themselves. Different from a straightforward ethogram, this is similar to the current wok in ecosemiotics, which analyses how humans interact with and perceive both the environment and other species. This can be used to translate animal behaviours to give them meaning, rather than a simple ethogram which lists behaviours. Indeed, such work is already taking place in animal welfare; for example, Dyson et al. (2018) developed a specific ethogram of behavioural markers which indicate pain (part of the Innenwelt) in ridden horses.

With respect to behavioural markers, physiological measures (related to the Innenwelt) can also be taken and then correlated with behavioural data, such as heart rate, respiration rate and corticosteroid levels, in order to validate the interpretations of behavioural data. Indeed, neurotransmitter metabolites have also been used to validate measures of motivational-emotional states and traits in humans (Kruesi et al., 1990), and fMRI studies can be used to record brain activity in non-human animals (Cook et al., 2016). Thus, there is the possibility of researching pattered signals at different levels of cellular organization, from whole organism signalling to cellular communication, to genomic DNA codes. 


\section{c) Ecological Game Theory}

Thus far, I have treated emotion and cognition studies as separate entities, but there can be cross- over in paradigms and methodologies, depending on the research question. Examining the interplay between cognition and emotion further, behavioural ecology studies often investigate a different set of variables to animal welfare studies, and economic theories have been adapted to investigate decision making processes in animals. These decisions are based upon a mixture of cognitive and emotional processes. Economic Game Theory (Myerson, 1999), for example, was adapted from Nash's original non-cooperative economic theory, by Maynard-Smith in (Smith, 1979), who applied the mathematical concept to behavioural ecology and evolutionary biology. The theory predicts how an animal's behaviour can maximize benefit to an individual, whether it be behaviour involved in reproduction, foraging, aggressive encounters, or predator avoidance. It is a complex interplay of emotional value-based judgements and cognitive logic- based predictive assessment. For animal contests, 'Game Theory' uses terms to indicate how an animal 'plays' during contests. An animal who will tend to posture but not attack, and then retreat or submit is termed to be playing 'Dove', whilst an animal who will tend to attack is termed to be playing 'Hawk'. Thus, by assigning values to contest outcomes (win, lose or draw) the net benefit for each individual should maximize its 'pay off' (with respect survival or reproduction), within a population where the two contest strategies are in equilibrium. However, more recent data suggest that it does not appear to be straightforward. There are ethological studies investigating the signs and social signals on which animals rely when deciding on contest strategy, such as the phenomenon of 'song overlapping' as an aggressive signal in songbird species, investigated by Naguib and Mennill (2010) and Arnott and Elwood (2009) which investigates the phenomenon of 'self-assessment', based upon the outcome of previous encounters during contest behaviour. Therefore, during hostile encounters, animals do appear to pay attention to signs, signals and consolidated memories when deciding on strategy.

As there is evidence to suggest that semiosis is involved in economic reproductive and survival strategies, it is possible that in biosemiotic studies, 'Game Theory' could be adapted to focus on signs and signals of aggression/attack and submission/ avoidance, rather than the individual's behaviour itself. This includes the linguistics of animal communication, such as the semantic elements of birdsong (Kunc et al., 2006) as well as phenomena such as the 'dear enemy effect' (Booksmythe et al., 2010). This is where coalitions with a shared, mutually beneficial goal work together, and the goal itself can be treated as a Peircean referent. However, coalitions could break- down very quickly in the absence of social bonds, meaning that apparent co-operation, when viewed semiotically, could actually be an aggressive/ competitive interaction. Conversely, examples such as those in Jarošs (2016) accounts of domestic cat colonies, demonstrate that apparent conflicts are not always related to competition, and can be affective or personality type (Dingemanse et al., 2010; Koolhaas et al., 1999), or may be due to underlying pain, injury, or disease process (Mills et al. 2020). Perhaps a focus on an 'object' or referent (in the case of 'Game Theory', the resource apparently under dispute) as opposed the individuals involved, could therefore shed new light on social interaction. 
d) Play- back Experiments.

Play- back experiments are commonly used in behavioural ecology, both in the laboratory and field. The design of a play- back experiment involves a sign or social signal being artificially reproduced and manipulated, then presented to an individual. The signal can be acoustic, such as calls and bird song; visual, such as feather plumage colouration, or olfactory, for example, pheromones. The behaviour of the focal individual(s) (or 'sign interpreter') is then analysed and recorded, and this includes recording any vocalisations and kinesics produced in response to the presented signal. For further reference and more detailed information, a review of the design of playback paradigms is given by McGregor (2000), and a primer on acoustic play-back experiments is provided by Fischer et al. (2013).

A good example of how these studies can be useful in biosemiotics is demonstrated in studies on the nightingale broadband trill. Trills and rattles are common in bird signals, so to investigate the signals' meaning, Schmidt et al. (2008) performed a playback experiment with male nightingales, Luscinia megarhynchos. The broadband trill signal was isolated from the nightingales' song and manipulated before being played back. The authors were then able to deduce the aggressive meaning of the signal, both to the signaller and interpreter, from the behaviour of the interpreter, or the signal's effects on subsequent behaviour and reproductive success.

Moreover, these paradigms can be used in aquatic species. For example, Sayigh et al. (1999) used play-back experiments to investigate individual recognition in bottlenose dolphins, concluding that mothers and independent offspring were able to recognise each other from their whistles, using a play-back study along with a behavioural analysis. Thus, the signal had specific meaning to the signal interpreter, and because this phenomenon was investigated in a study population instead of just two focal individuals, it suggests that each signal must therefore be unique.

To summarise, fundamental and structural elements of animal signals from different species can be examined, before investigating meaning. 'Menaing' can be inferred or even deduced from context, as well as from the behaviour of the interpreter. Thus, playback experiments, adapted to Umwelt theory and semiotic theory, would be of significant promise in advancing zoosemiotics and ethology, because the behavioural response of the interpreter of a sign or social signal can be employed to elicit the meaning of the sign/signal. Thus, from the researcher's perspective, the interpreter's response becomes the representamen of a referent (or construct) within the Innenwelt of the receiver. This, in turn, provides an indication of the signal's meaning when taken in context- the context being the receiver's Umwelt. Moreover, the absence of a behavioural response to a signal is, in itself, a behavioural event. In fact, even when a behavioural response is apparently absent, a very subtle response such as a change in blink rate (Merkies et al. 2019) may be revealed on closer examination, using software such as 'Solomon Coder', and techniques such as infra- red thermography can reveal reactive changes in body temperature (Yarnell et al., 2015).

e) Waveform and Spectral Analysis

Waveform and spectral analysis can investigate any known energetic phenomenon, but most usually photic or acoustic. It is a useful tool for investigating the physical 
properties of audible and visual signs and signals and is often employed alongside acoustical play-back experiments.

The following synopsis is an example of how waveforms can be studied quantitively as signals, and the meaning elicited from those signals. It is a brief description of a quantitative experimental methodology which tested for Morton's MotivationalStructural Rules in bird calls, using acoustical spectral analysis. This synopsis is presented as an illustration of the kind of quantitative methodologies are available and the potential versatility. Whilst it was not designed as a semiotic study, it has been annotated to demonstrate how easily the methods could be adapted:

\section{Testing for Morton's Motivational-Structural Rules in Bird Calls}

E.S. Morton's 'Motivational-Structural Rules' (MS Rules), (1977), predict the acoustic parameters of bird and mammal vocalisations, according to the underlying motivational state of the signaller. Indeed, Morton, (1977), postulates that short-range calls may reveal information about the underlying motivational-emotional state of a signaller in a specific context. Specifically, the MS Rules' predict that the acoustic structure of bird and mammal vocalisations are both indicative of an individual's underlying motivational state and shaped by the context in which the vocalisation occurs; for example, 'friendly' or 'hostile' encounters. [In this example, using the Peircean tripartite framework, the motivational-emotional state of another individual is the 'object'; the representamen is a vocalisation, a visual signal such as an approaching predator, or an olfactory cue such as the scent of a conspecific, which has meaning to the signal's interpreter. In response, the interpreter then produces a signal which has meaning to the researcher according to the underlying motivational state. It is two chains of sign processes, one involving the non-human animal agents; one involving the researcher].

In his hypothesis, Morton goes on to propose two broad motivational categories resulting from the signal's interpretation, 'approach' or 'repel'. These categories reflect the likelihood an animal will either flee or attack in response to a hostile encounter and thus can be further delineated by separating emotional 'fearful' from 'aggressive' motivation [or in biosemiotic terms, interpretation of the signal. Thus, the meaning of the signal produced is elicited from the signaller's underlying inferred motivationalemotional state]. The MS Rules predict that fearful and appeasing vocalisations have high frequency, pure tones with low bandwidths. Conversely, aggressive vocalisations are postulated to be low frequency, harsh tones with high bandwidths. Significantly, both motivational states involve negatively valenced emotional states occurring in hostile situations. Whilst there is some limited support for Morton's theory in mammal species, the evidence is equivocal, and comprehensive studies in birds are scarce. I therefore tested for Morton's MS Rules in bird calls across avian taxonomic groups. The methodology used is as follows:

Acoustic data [patterned signals] was collected, on the minimum and maximum frequencies, bandwidth, duration, and number of vocal elements from spectrograms of context-specific bird calls, across bird taxa. I used the primary scientific literature as my data source, by using web- based data bases and search engines, including Google Scholar, Web of Science, Science Direct and Scopus. My search criteria included different combinations of 'bird' OR 'avian', AND 'alarm' OR 'fear'; 'aggressive' OR 'territorial'; 'mating' OR 'mate attraction'; AND 'vocalization' OR 
'communication' OR 'call'. This resulted in a diverse selection of samples from different taxa across the globe. The vocalizations were categorized into 3 groups, according to the inferred underlying construct [and thus, meaning]. Alarm [meaning 'fearful'] and aggressive [meaning 'intent to repel or attack'] vocalisations were the two experimental groups and are indicative of negatively valanced emotional states. Mating vocalizations, [with a meaning which can be summarized as 'attraction'] formed the control group because they are appetitive or contact calls, and thus positively valanced signals [biosemiotic study may well reveal that 'appetitive' and 'contact' calls have elements of frustration and/or unpleasant sensations such as hunger, leading to a complex mix of meanings which cannot be discretely categorised as 'positive' or 'negative']. I then tested the acoustical data using Phylogenetic Generalized Least Squares analysis in ' $\mathrm{R}$ ', which controlled for similarities between phylogenetic groups and thus body size, the latter being a critical component of the Motivational-Structural Rules theory.

A web-based tool 'WebPlotDigitizer' was used to retrieve acoustic spectral data from the spectrograms. Before performing the PGLS analysis, a phylogenetic tree was created for the species data, using the web- based application 'BirdTree'. The graphical representation of one tree [a sign representing patterns of species over evolutionary time] was then saved as a text file in Newick format before being imported into R. The PGLS analysis then produced models for each single acoustic parameter.

\section{Results}

There is no significant effect of context on maximum frequency between mating calls and aggressive calls; mating calls and alarm calls, and alarm calls and aggressive calls: ANOVA: $\mathrm{DF}=1,49 ; \mathrm{F}=3.063 ; p=0.086$. Similarly, the results for minimum frequency showed no significant results: $-\mathrm{DF}=1,49, \mathrm{~F}=0.121, P=0.86$; nor was bandwidth affected by context: - ANOVA: $\mathrm{DF}=1,49, \mathrm{~F}=2.81, P=0.0696$. With respect other metric parameters, there were no significant results for either the number of vocalisation elements: - ANOVA: $\mathrm{DF}=1,49, \mathrm{~F}=1.15, P=0.288$; or duration of the vocalisation: - ANOVA: $\mathrm{DF}=1,49, \mathrm{~F}=2.91, P=0.064$. There is no significant difference between the acoustic parameters of calls across the three motivational contexts (Fig. 2, pages 31-32, a-e). Frequency- related parameters share similar median values, are the closest to the fitted values of the PGLS model and have a higher log likelihood. The number of call elements and the duration are less well fitted to the PGLS models (Fig. 3, page 33, a-e). Moreover, for the 'number of elements', there may be a trend, as the median value is lower for alarm calls than aggressive \& mating calls. However, the LogLik value suggests this result is less likely than the frequency-related and duration results.

\section{Conclusion}

The results of the study do not support Morton's Motivational- Structural Rules theory in avian taxa (i.e., in semiotic terms, the acoustic structure of a signal produced in hostile situations, which thus has either a fearful or aggressive meaning, cannot be 


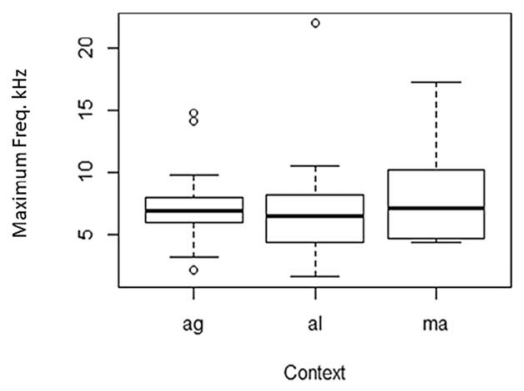

a)

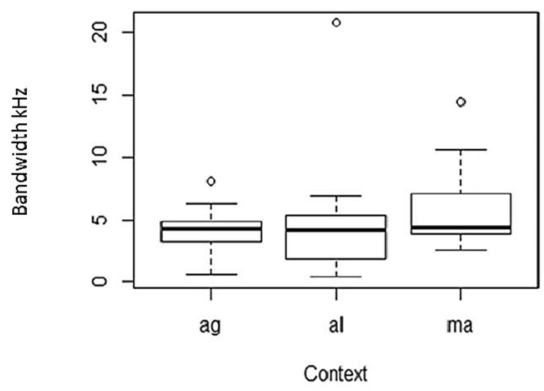

c)

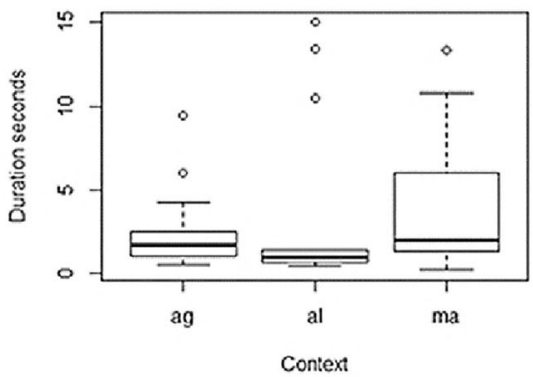

e)

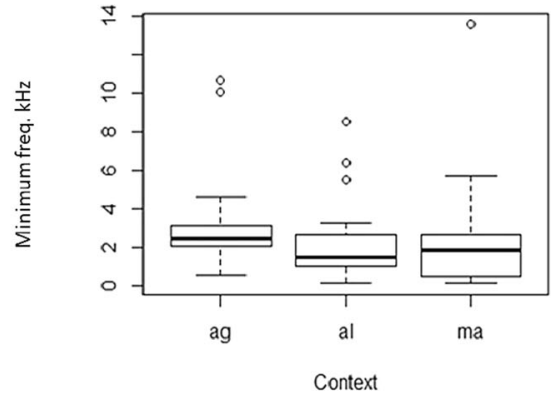

b)

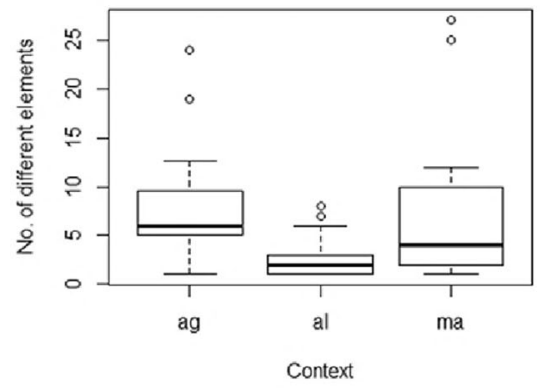

d)

Fig. 2 Box plots of acoustic parameters, Y axis:- a) Maximum frequency (kHz); b) Minimum frequency $(\mathrm{kHz})$; c) Bandwidth $(\mathrm{kHz})$; d) number of elements (metric); e) duration (seconds), against 'category' on $\mathrm{x}$ axis:- 'al', alarm vocalisations; 'ag', aggressive vocalisations; 'ma', mating vocalisations

predicted). However, further study with a larger sample size, and including acoustic measures such as amplitude, may be beneficial.

This simple study indicates how studying the patterns of signals (either waveform or molecular) could lead to significant advancements in the field of biosemiotics, and this is a technique which can be used in conjunction with other methodologies to elicit the meaning of signs and social signals. Indeed, computer programs such as 'Praat' phonetics software can be used in acoustical analyses to investigate the structure of vocal signals (Ravignani, 2018). Moreover, specialist cameras, including infra- red thermography cameras (McCafferty et al., 1998), and cameras which detect UV light, (Papiorek et al., 2016) are used in studies to investigate waveforms and energetic phenomena invisible to humans. Thus, technological advances mean we can have a 
a)

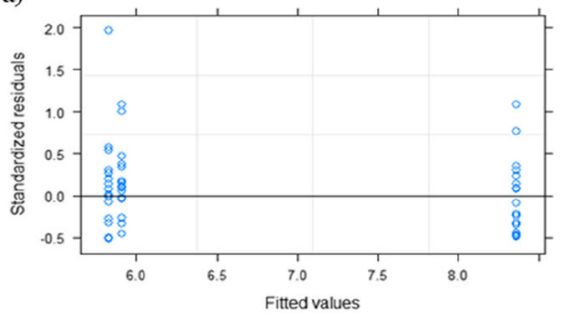

c)

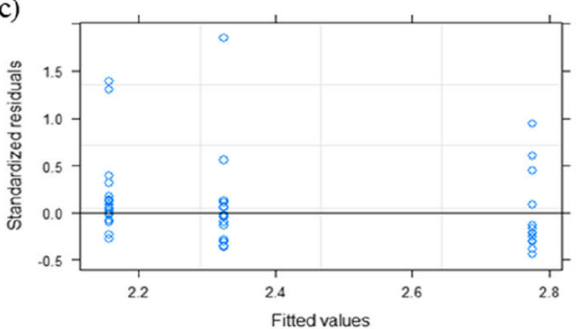

e)

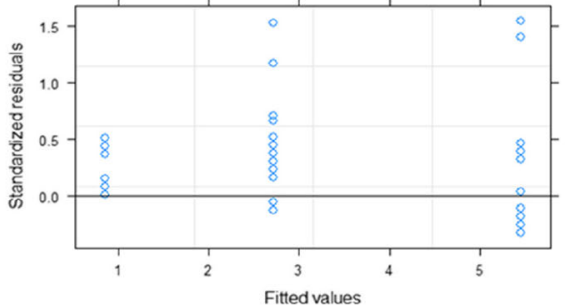

b)

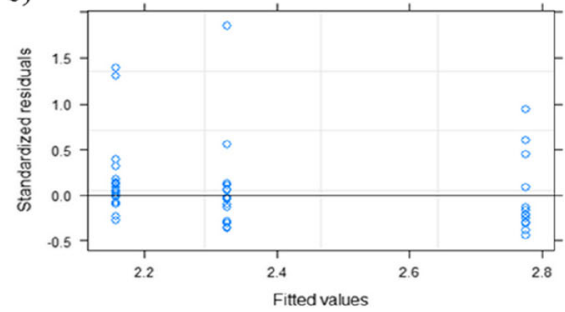

d)

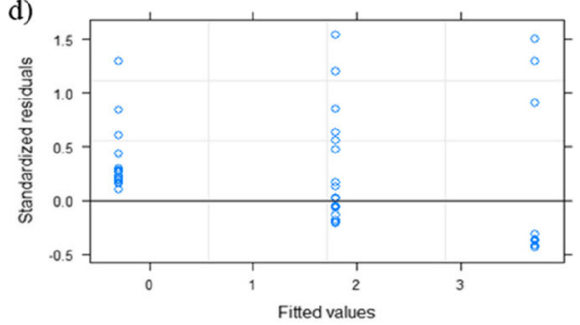

Fig. 3 PGLS models for 5 contextual categories:- a) Maximum frequency (kHz); b) bandwidth (kHz); c) minimum frequency $(\mathrm{kHz})$; d) duration (Secs); e) number of different vocalisation elements. The distribution of standardised residuals, which are the difference between the sample population values and the sample population mean, are shown on the $\mathrm{Y}$ axis. The standardised residuals are plotted against the fitted values, which are the population values as predicted by the PGLS model and are shown on the $\mathrm{x}$ axis

greater understanding of the Umwelten of other species by mimicking their sensory capabilities. However, when semiotic theory is incorporated into traditional ethological paradigms, the results could be instructive and reveal valuable avenues which are yet unexplored. For example, the MS Rules assume that hostile encounters can be categorized according to fearful or aggressive motivation. However, what happens when the agency of the individuals involved is recognized?

Significantly, in biosemiotic studies, individuals are treated as having an identity and agency. If an individual has an identity, then they can be recognised by others, and indeed it has already been demonstrated in many animal species that individuals can recognise other individuals or groups (Yorzinski, 2017). By considering individual signatures, signalling and agency as being significant, it can be assumed that individuals therefore have the role of 'friend' or 'foe' in a close-range hostile encounter. Morton's MS Rules can be developed thus:

a) A 'friend' who has caused injury or irritation, would stimulate an alarm call or aggressive call with the meaning: 
- Fearful, high frequencies- "come here, so that we can mend the social bond" (approach)

- Aggressive, lower frequencies- "go away and leave me alone, for now" (avoid; time limited)

b) A 'foe' would be a threat, either through loss of resources or the risk of bodily injury, or both. The meanings of the calls would change to reflect this:

- Fearful, high frequencies- "please go away and leave me alone- there is no challenge/ I submit (avoid) OR "help!" (call to allies, approach)

- ii) Aggression/very low frequency- "come here, because I'm going to attack you. In English speaking countries, humans quite literally do this during inter-personal conflict, when they say, "come here and say that!", indicating physical punishment is about to be meted out in response to a perceived transgression.

This may well be why support for the MS Rules in the ethological literature is, at best, equivocal. Moreover, the theory is fundamentally flawed, because it assumes 'avoid' signals only happen in 'hostile' contexts, whilst in actuality, avoid signals can happen in a variety of contexts, as can approach signals.

In summary, many experimental paradigms such as 'Go/No-go' have largely been based upon learning theory, and the behaviourist ideas of 'reward and punishment' (instead of animals' experiences in their complex Umwelten and Innenwelt). Nonetheless, in their present form, they are tools which give an accurate, but not precise approximation of an animal's Umwelt. For example, Bethel and Kayama, (2015, pp. 2-3) state that "Within Mendl et al.'s [10] integrative framework, emotional valence is directly associated with approach towards reward (associated with excitement and happiness) and avoidance of (or inhibition of response to) threat or punishment (associated with fear and anxiety)". This is likely true; however, it does not account for more complex interactions of an individual with agency, who is analysing and responding to complex patterned signals and multidimensional emotional states (where more than one emotion is experienced simultaneously) rather than simple binary choices and one-dimensional emotional states.

Nonetheless, current quantitative ethological paradigms are formalized frameworks with metrics which lend objectivity to interpretations of another individual's subjective experiences. Further, these studies rely on sample populations, which means that many individuals within a study yield the final data set. Thus, studies can be more focussed with respect the specific trait under investigation, because the data comprises measurements of one trait, replicated many times, to maximize available data points i.e., the research focus can be 'narrowed down'. Such a reductionist approach is useful in disentangling complex, dynamic systems, before reassembling the separate parts again as part of a holistic approach.

For biosemiotic study, the next stage would be to apply more refined qualitative techniques, such as those exemplified by Tønnessen (2009), who discusses in depth the behaviour of two individual cats and their interactions with humans, from his own personal knowledge of those individuals. Nevertheless, Jaroš and Maran (2019) highlight the tendency for researchers in comparative psychology, who use both quantitative and qualitative methods, to interpret evidential data in terms of a narrative. The authors propose models from which to analyse quantitative theories in comparative psychology, 
from within the framework of the specified, relevant narrative. However, risks of data interpretation which follows a narrative can be minimised by robust experimental design, using appropriate paradigms, and limiting the conclusions reached to those supported by the data, before engaging in qualitative assessment. Moreover, these paradigms could be adapted to the Peircean tripartite model of semiosis to investigate animal sensory perception, which moves the focus away from the organism and toward the sign itself, reducing the risk of 'uncritical anthropomorphism'. This is a term defined by Burghardt (1999) as "Attributing human characteristics to nonhuman entities. Often this is carried out in a loose and sloppy manner, leading to anthropomorphism being considered a major sin to be avoided at all costs in the study of animal behavior or comparative psychology". Furthermore, employing Umwelt theory and embodied cognitive theory could shift paradigms toward data analyses using multi-dimensional pattern recognition of complex traits in non-Euclidean space, rather than working on the binary paradigms of 'reward' and 'punishment', represented in a Euclidean space.

\section{Literature Reviews of Existing Ethological Studies}

There is a vast body of data in the peer reviewed literature covering traditional animal behaviour, welfare, and ecology. Study paradigms are varied, and animal behaviour is a diverse field which encompasses farm and laboratory animal welfare, companion animal behaviour, comparative psychology, behavioural ecology, marine biology, and population ecology, to name but a few. This list is by no means exhaustive, and the majority of studies are quantitative in nature, and almost without exception, assume the Modern Synthesis. Methodologies vary from those which employ the paradigms listed previously in this paper, to evolutionary 'tree of life studies', mathematical modelling, and various other different quantifiable perspectives on animal behaviour. Nonetheless, cohesion would be beneficial, and studies are currently disparate in their approach. At the present time, true interdisciplinary work is not commonplace, although there is input from external fields such as mathematics and engineering, alongside the utilization of paradigms and theories from the human psychology literature, and linguistics. Moreover, whilst the terms of traditional ethology do not match semiotic terminology, and the concepts do not follow semiotic theory, the data can nonetheless be reinterpreted from within a semiotic framework.

However, whilst the data can be reinterpreted, it is important that it is not distorted, so that it maintains its accuracy and is not misinterpreted. Significantly, with respect terminology, many apparent conflicts could well be a matter of precision and accuracy, with traditional ethological terms such as 'cue' or 'receiver' having approximately the same meaning as Peircean 'signs' and 'interpretant'. Whilst there are important yet subtle distinctions, this is not a barrier to translating ethological concepts. Skilful reinterpretation and precise definitions, along with explanations of how the data can be reinterpreted, are required. This process can successfully marry the cultures and frameworks within ethology to biosemiotic theory. No meta- analysis of the quantitative data is necessary (although it would be possible, if necessary and appropriate), and once in a semiotic framework, reinterpretation and global conclusions are not only possible, but beneficial with respect biosemioticians' ability to use the existing data and scientific evidence. 
Furthermore, once the data has been brought together to reach semiotic-based conclusions, the resulting hypotheses which can be generated can be tested using predictive mathematical models, and by modelling empirical data. Indeed, neither the Modern Synthesis nor the data from traditional ethology, ecology and animal welfare need be valueless to biosemiotics. The data are simply, as phrased by Hoffmeyer (2011), 'immature', or as I would prefer to term it, 'unassembled'. The Modern Synthesis requires updating, but it is not necessary to first 'reinvent the wheel' to do so. Biosemiotics can update existing theories and paradigms, thus creating a 'Semiotic Modern Synthesis' which draws from, but preserves, neo-Darwinist theory, whilst also incorporating the evolution of signals and individual agency. Significantly, however, the Modern Synthesis provides context which, broadly speaking, involves complex patterns of either 'approach' or 'avoid' and 'synergism' and 'antagonism', the latter usually being referred to in traditional ethology and evolutionary biology as 'cooperation' and 'conflict' (respectively), within the Umwelt.

\section{Discussion}

Despite the development of biosemiotics as an interdisciplinary field, biology and semiosis are widely still viewed as separate fields of enquiry, but in the future this could change. It is possible to bridge the gap between traditional biology and biosemiotics, by incorporating quantitative methodology. Quantitative behavioural studies reveal a wealth of data, and with careful reinterpretation, it is possible to use this data to identify signs and signals in the semiosphere, which have meaning, particularly in the case of social signals. Thus, we can derive valuable insights with respect animal Umwelten and Innewelten. Moreover, this framework also allows for evolutionary studies on communication and social signalling to evaluate how the 'meanings' of animal signals may have changed. Studies investigating the changing structure of signals are not uncommon, but specifically why this occurs in relation to the sign or signal's individual interpreters is an unknown. For example, as mentioned in the introduction, during sympatric speciation events, the meaning of mating signals must change for the interpreters. This prevents animals of two diverging groups from mating, but although theories have been postulated; for example, changes in beak morphology could alter mating vocalizations in songbirds, how and why this happens, (for example, how changes in male songbird vocalizations would operate with respect the female interpreters), is unclear. Furthermore, recent studies on anthropogenic noise, such as Kunc and Schmidt (2020) investigate how anthropogenic acoustic noise interacts with and affects animal signals. Not only is this important with respect more obvious functions such as echolocation and interruption of mating signals, but if animals are forced to alter the structure of their vocalizations, then this could well alter the meaning. This will likely lead to breakdowns in inter-specific communication, perhaps in ways humans have not yet been able to anticipate.

Moreover, reframing animal behaviour paradigms would be beneficial in selecting and designing appropriate quantitative research methodology. For example, one of the paradigms used to investigate the human-animal bond and the premise for 'separation related issues' is the Ainsworth Strange Situation Test (SST) described by Ainsswirth et al. (1972), which assumes that dogs, cats and other domestic species play the role of 
'infant' whilst the owner or caregiver assumes the role of 'parent'. Indeed, this assumption has become pervasive. In Lewis (2020b), the relevant published evidence is reviewed and used to challenge the assumptions made in using the SST. The risk that it is inappropriate to assume that dogs display infantile behaviour, and that such paradigms and assumptions are potentially deleterious because they promote emotional immaturity and a lack of resilience, is also discussed. Moreover, by defining social bonds in terms of a study designed to test parent-juvenile attachment, it is possible that mature, adult social bonds which do not conform to the experimental criteria are being disregarded.

However, Jaroš (2017), challenges the assumptions adopted by the authors of an SST cat-human study by Potter and Mills (2015); namely, that cats are relatively solitary and autonomous, thus do not rely on their human companion for emotional support. The employment of a semiotic framework by Jaroš (2017), which was initially proposed by Burghardt, (1998) (Burghardt 2008, citing Burghardt 1998), demonstrates that cats do show features of affiliative and social behaviour, including joint attention and cooperation, which are observable when using Peirce's tripartite model of semiosis. However, Jaroš's study does not impose a paradigm on the cats, and indeed such practices in traditional animal behaviour inevitably lead to logical fallacies, i.e., 'these cats do not behave the same way as a dog or a child in this experimental situation: this experimental paradigm shows that dogs and children can have secure attachment to their owner or parent: therefore, cats do not show secure attachments to their owners'. Indeed, representing Pierces' tripartite model as a mathematical function aims to reduce such failures which are due to prima facie linguistic logic. Certainly, the conclusions of Jaroš's (2017) study and Jaroš's (2016) analysis and proposal of a 'tri-constructivist' approach are consistent with the conclusions of Lewis' (2020b) analysis of domestic dog social behaviour, which identifies the animal-human bond as being different from parent/juvenile attachments. Significantly, Jaroš (2017) allowed the cats to inform the observer/ researcher what was significant to them, in their Umwelt, with respect how they implement their social bonds. Moreover, Jaroš (2016), concludes that cats have their own perception of humans, based upon what we may represent (signify) to them i.e., emotional warmth and companionship.

However, the problem with qualitative study on its own, is that it is not demonstrated that observations would be repeatable i.e., observations may be an anomaly of the specific study population which, whilst valid, cannot be generalised to other cats. This is evident in Jaroš's (2016) discussion of three long-term studies, performed by different researchers, who studied separate social groups of domestic cats, all in differing environments and circumstances. Further, another observer may interpret the data from qualitative studies differently. The solution would therefore be to employ observational methods such as those described previously to quantify data such as Jaroš's (2017) findings, and then repeat the study with different study populations and observers. Moreover, it would be possible to adopt Jaroš's (2016) tri -constructivist approach as a meta-analysis methodology in both animal behaviour, and animal welfare science in the same way that ecosemiotics has been developed as an integrated semiotic approach to ecosystem biology and human culture.

Nonetheless, an emphasis on qualitative studies involving animals risk placing too much emphasis on subjectivity (and potentially, anthropomorphism and human imagination), leading to the risk (although not inevitability) of a failure of common-sense 
reasoning (creativity is, after all, a peculiar talent of human beings). For the purposes of studying animal Umwelten and Inenwelten, it is reasonable to assume that an objective reality exists, even if it is interpreted by individuals as a subjective experience. That may change in the future, but given the current knowledge accrued within the physical sciences, it is the best assumption on which to work when studying other species. Consequently, mathematical models can test pattern-forming relationships between objects after logical verbal or written arguments and hypotheses have been made. Mathematics, after all, describes the relative positions of Peirce's 'referents' and of 'signs' and 'signals' in space and time, as we perceive those phenomena. Significantly, there has also been a move away from reductivism toward holism, and whilst the proliferation of reductionist data on its own means little, like the pieces of a jigsaw puzzle, it can be put together to form a holistic picture. Without the reductionist methodology, then it would be difficult to elicit how complex biological systems function, as they are a web of many complex localized phenomena interacting dynamically. Only by examining the local phenomena is it possible to elicit the function of the whole.

Significantly, however, without additional qualitative study, all which can be revealed is a series of patterns in data, which may lead to conclusions, but which have no real meaning. Indeed, traditional ethology already relies on subjectivity and qualitative data by assigning 'contexts' and 'motivations' (and thus, meaning) to behaviours. Therefore, a combined analysis in biosemiotics is key to understanding the Umwelten and Innenwelten of other species.

To put this into a demonstrable perspective, how is it possible to define and quantify concepts like 'aggression'? Perhaps if another individual is harmed? If so, how does one account for rough and tumble play bouts, where an individual is injured accidentally, or one partner is enjoying the interaction, but the other is afraid? Traditional ethology describes perceived context and infers motivation, but again, it is difficult to identify and reliably define another individual's motivation. For example, if an individual is observed running from point $\mathrm{A}$ to point $\mathrm{B}$, is it running away from point $\mathrm{A}$, or to point B? Here, there is a distinction between 'approach' and 'avoid', which might be elucidated from the behaviour's context (the Umgebung), or from the agent's perspective, the Umwelt. For example, a dog running in random patterns of movement in the safety of its garden, with relaxed body posture, and occasionally 'leaping', all occuring in the absence of any danger signal, could be inferred to be positively motivated, 'joyful', 'happy', or 'playful'. However, with respect motivation, there are subtle differences in the emotional 'valences' which drive behaviour. Consider the previous example of observing a running dog, and this time assume a negatively- valenced emotion, derived from a potentially hazardous context. In such a situation, it is possible for there to be a distinction both between contexts, and between arousal levels (e.g., fear and anxiety as motivating emotions). For example, a dog running from another dog which is chasing it may be experiencing fear of attack and will simply run away from its pursuer to escape harm. Meanwhile, a dog feeling anxious in a thunderstorm may run for home where it cannot escape the sign which prompted it to flee (it can still perceive the acoustic sign of thunder) yet it feels safer having taken shelter in a familiar place. Situations like these can only realistically be addressed with qualitative data, given the vast number of variables involved, some of which may be unique to each individual situation and each individual animal. 
Nonetheless, what we do know is that we have made observations of thousands of dogs over evolutionary time. Taking an average or median, we know that dogs run, and that they run when they are afraid, anxious, aggressive, happy, and playful. One dog alone would not be sufficient to say that running is a behaviour we see in dogs as a species generally, yet it is the necessary starting point for further study. Furthermore, if a dog is running, then it is forming patterns, such as a 'Random Walk'. By using quantitative or pattern recognition methods, and with sufficient data, we can perhaps delineate between the path of a dog running in fear, and a dog who is running playfully. This is a simplified example, which demonstrates the benefits of quantitative alongside qualitative study, but the premise is that quantitative data is necessary to underpin the qualitative assessment.

Significantly, though, this is not a one-way process; a semiotic approach could benefit traditional ethology when answering Niko Tinbergen's 'four questions' (Bateson \& Laland, 2013) which address mechanism, ontogeny, causation, and survival value when studying animal behaviour, because these phenomena are fundamentally all based on sign processes at different levels within a complex Umwelt. Thus, it should be possible to shift the focus from individual phenotypic traits to signs and intentional signals. Indeed, I would add a further question- "what is the motivation?" 'Desire' and 'appreciation' are motivating factors which may in some instances have their roots in evolutionary adaptations, physical properties, and developmental pathways, yet as a stand- alone entity "because I liked it", with no associated cost or benefit other than subjective feelings of aesthetic appreciation, perhaps should be considered. Indeed, such are the peculiar aesthetic properties of 'The Golden Ratio' and the Fibonacci sequence (Meisner, 2018).

Furthermore, it should be noted that the paradigms listed in this paper are often used in combination; for example, a play-back study may also involve spectral analysis and behavioural observations. By combining techniques, quantitative analysis can reveal spatial and temporal patterns, whilst qualitative analysis can infer or deduce meaning. Further, a combined framework based upon a 'Semiotic Modern Synthesis' would unite the Umwelt, Innenwelt and Umgebung without simply joining every individual together on a 'normal curve', to form a continuum where only averages and medians matter, outliers are disregarded, and individuals have no significance. Additionally, a combined approach also leaves room for development and future reinterpretation of empirical data, and an adaption of statistical methodologies to three- dimensional pattern recognition, rather than two- dimensional Euclidean geometry.

To achieve this end, I propose using Sebeok's framework for zoosemiotic research (Maran, 2017, citing Sebeok, 1990):-

“A good example of such an approach is Thomas A. Sebeok's (1990b: 111-112) zoosemiotic research framework that consists of six questions: 1. How does an animal that acts as a sender formulate and code a message?

2. How are messages transferred, through what channel and under what circumstances? 3. How does an animal that acts as a receiver in the communicative situation decode and interpret the message? 4 . What is the possible repertoire of a specific species? 5. What are the properties of the code as used by a specific species? 
6. What is the meaning of messages and, relatedly, what role does contextual information play in interpretation?"

- to conduct quantitative analyses in zoosemiosis, using techniques and methodologies described in this paper, alongside qualitative studies, thus forming a 'Semiotic Modern Synthesis'. Indeed, Sebeok's questions have features of Tinbergen's Four questions, the difference being the focus is on the signal rather than the organism itself, and there is the additional element of meaning. Thus, the work in traditional disciplines simply needs updating and amalgamating.

To finalize, from a biosemiotic perspective, life is a subjective dynamic experience based upon objective physical phenomena, which forms measurable patterned signals. Thus, quantitative analysis needs to be part of the exploration of the phenomenon we know as 'life', alongside subjective qualitative observations. Hence, I propose combining paradigms in traditional ethology with semiotic theory, to establish a 'Semiotic Modern Synthesis' which describes a new evolutionary framework in which to study evolutionary and behavioural biology.

There is an English idiom which can be used to illustrate the premise of unifying quantitative and qualitative methods: to 'not see the wood for the trees' means to miss the bigger picture by focussing on minutiae. However, without the individual trees, there is no wood. Trees are the building blocks of the phenomenon we understand as a 'wood'. Similarly, quantitative and reductionist analyses can identify the patterns made by many trees in close proximity, to which qualitative analysis can then give meaning i.e., a 'wood'. Thus, this is why it is necessary to formulate a 'Semiotic Modern Synthesis'.

\section{Appendix}

1) The 'C-BARQ' (Canine Behaviour Assessment and Research Questionnaire) is an example of qualitative analysis which is quantified using data from questionnaires, and further information on the project can be found at: https://vetapps.vet.upenn. edu/cbarq/

2) 'Web Plot Digitizer' is a web- based application which can be used to extract data from graphs and is free to use: https://automeris.io/WebPlotDigitizer/. Similar applications include 'Data Thief', https://datathief.org/

3) 'Solomon Coder' is a behavioural coding software program, which is free to download and install: https://solomon.andraspeter.com/

4) 'Bird Tree' is a web- based resource for generating phylogenies for bird taxa: https://birdtree.org/

5) 'Fig Tree' is a web-based resource plots evolutionary trees and phylogenies: http:// tree.bio.ed.ac.uk/software/figtree/

6) ' $R$ ' and 'R Studio' are statistical and data handling software environments. They are free to download and install. The $\mathrm{R}$ environments rely on open- source code programming, and this type of data analysis is gradually replacing packages like IBM's SPSS platform. There are various training courses and books for using $\mathrm{R}$ and $\mathrm{R}$ studio, and code can be found online and in peer-reviewed published studies. Experienced users can write their own code to fit their requirements. $\mathrm{R}$ has many benefits, including versatility, packages for different analyses, graphical 
packages, and the ability to save all data analyses, so that other researchers can rerun the code using their own data. It also means that the code scripts can be uploaded into a repository, so the statistical analysis can be scrutinized and verified by peers. R can be downloaded: https://www.r-project.org/

6) Specialist companies such as Thermal Vision Research, Oxford, UK supply specialist imaging equipment to researchers in the biological sciences, with options available to rent cameras as well as buy: https://thermalvisionresearch.co.uk/

7) 'Praat' is a phonetics software, available to download online: https://www.fon. hum.uva.nl/praat/

8) 'Wildlife Acoustics's' bioacoustics sound analysis software, 'Kaleidoscope', can be found and downloaded here, along with bioacoustics training courses and webinars: https://www.wildlifeacoustics.com/products/kaleidoscope/ kaleidoscope-lite

Table 3 spectrogram source references, species and context of the vocalisations used to obtain acoustic data

\begin{tabular}{|c|c|c|c|}
\hline Reference & Species & Scientific name & Context \\
\hline Baker, 2006 & Western Gerygone & Gerygone fusca & mating \\
\hline Baker, 2006 & Red Capped Robin & Petroica goodenovii & mating \\
\hline Beani, 1995 & Partridge & Perdix perdix & mating \\
\hline Bretagnolle \& Lequette, 1990 & Cory's Shearwater & Calonectris diomedea & mating \\
\hline Cardoso, 2007 & Serin & Serinus serinus & mating \\
\hline Dakin \& Montgomerie, 2004 & Peacocks & Pavo cristatus & mating \\
\hline $\begin{array}{l}\text { Deregnaucourt \& Guyomarch, } \\
2003\end{array}$ & European Quail & Coturnix coturnix & mating \\
\hline $\begin{array}{l}\text { Deregnaucourt \& Guyomarch, } \\
2003\end{array}$ & Japanese Quail & Coturnix japonica & mating \\
\hline Eda- Fujiwara et al. 2016 & Budgerigar & Melopsittacus undulatus & mating \\
\hline Groth, 1993 & Crossbills & Loxia pytyopsittacus & mating \\
\hline Klenova et al. 2011 & Auklet & Aethia cristatella & mating \\
\hline Kunc et al., 2005 & Nightingale & Luscinia megarhynchos & mating \\
\hline Lein, 1980 & Ovenbird & Seiurus aurocapilla & mating \\
\hline Matessi et al. 2005 & Rock Sparrow & Petronia petronia & mating \\
\hline Nowicki \& Searcy, 2004 & Song Sparrow & Melospiza melodia & mating \\
\hline Pasteau et al. 2007 & Canary & Serinus canaria & mating \\
\hline Rehsteiner et al. 1998 & Water Pipit & Anthus spinoletta & mating \\
\hline Riede et al. 2015 & Sandpiper & Bartramia longicauda & mating \\
\hline West et al. 1998 & Cowbird & Molothrus ater & mating \\
\hline Blaich \& Miller.1988 & Mallard Duck & Anas platyrhynchos & alarm \\
\hline Conover, 1994 & Red Winged Blackbird & Agelaius phoeniceus & alarm \\
\hline Conover, 1994 & European Starling & Sturnus vulgaris & alarm \\
\hline Goodale \& Kotagama.2005 & $\begin{array}{l}\text { Ashy Headed Laughing } \\
\text { Thrush }\end{array}$ & Garrulax cinereifrons & alarm \\
\hline Goodale \& Kotagama.2005 & Yellow Browed Bulbul & Pycnonotus xantholaemus & alarm \\
\hline Goodale \& Kotagama.2008 & Orange Billed Babbler & Turdoides rufescens & alarm \\
\hline
\end{tabular}


Table 3 (continued)

\begin{tabular}{|c|c|c|c|}
\hline Reference & Species & Scientific name & Context \\
\hline Griesser, 2008 & Scrub Jay & Aphelocoma coerulescens & alarm \\
\hline Gyger et al. 1997 & Chicken & Gallus gallus & alarm \\
\hline Haftorn, 2000 & Willow Tit & Parus montanus & alarm \\
\hline Lowry, 2012 & Noisy Miner & Manorina melanocephala & alarm \\
\hline MacGrath et al. 2009 & Scrub Wren & Sericornis frontalis & alarm \\
\hline MacGrath et al. 2009 & Honey Eater & $\begin{array}{l}\text { Phylidonyris } \\
\quad \text { novaehollandiae }\end{array}$ & alarm \\
\hline Satischandra et al. 2007 & Greater Racket Tailed Drongo & Dicrurus paradiseus & alarm \\
\hline Suzuki, 2016 & Japanese Great Tit & Parus major & alarm \\
\hline Akçay et al. 2015 & Song Sparrow & Melospiza melodia & aggression \\
\hline Benedict et al. 2012 & Canyon Wren & Catherpes mexicanus & aggression \\
\hline Bradley \& Mennill, 2009 & Rufous Naped Wren & Campylorhynchus rufinucha & aggression \\
\hline Byers, 2017 & Chestnut Sided Warbler & Dendroica pensylvanica & aggression \\
\hline Couchoux \& Dabelsteen.2015. & Blackbird & Turdus merula & aggression \\
\hline Dabelsteen et al. 1997 & Robin & Erithacus rubecula & aggression \\
\hline Dubois \& Martens, 1984 & Large Billed Leaf Warbler & Phylloscopus magnirostris & aggression \\
\hline Dubois \& Martens, 1984 & Greenish Warbler & Phylloscopus trochiloides & aggression \\
\hline Dubois \& Martens, 1984 & Ashy Throated Warbler & Phylloscopus maculipennis & aggression \\
\hline Dubois \& Martens, 1984 & Buff Barred Warbler & Phylloscopus pulcher & aggression \\
\hline Dubois \& Martens, 1984 & Yellow Browed Leaf Warbler & Phylloscopus inornatus & aggression \\
\hline Dubois \& Martens, 1984 & Blythe's Leaf Warbler & Phylloscopus reguloides & aggression \\
\hline Dubois \& Martens, 1984 & Tickells Leaf Warbler & Phylloscopus affinis & aggression \\
\hline Dubois \& Martens, 1984 & Pallas's Leaf Warbler & Phylloscopus proregulus & aggression \\
\hline Funghi et al. 2015 & Serin & Serinus serinus & aggression \\
\hline Hamao et al., 2011 & Great Tit & Parus major & aggression \\
\hline Linhart et al. 2013 & Ciffchaff & Phylloscopus collybita & aggression \\
\hline Menill \& Ratcliffe, 2004 & Chickadee & Poecile atricapillus & aggression \\
\hline Proppe \& Ritchison, 2008 & Grasshopper Sparrow & Ammodramus savannarum & aggression \\
\hline Schmidt et al., 2008 & Nightingales & Luscinia megarhynchos & aggression \\
\hline Tietze et al. 2008 & Treecreeper & Certhia familiaris & aggression \\
\hline
\end{tabular}

\section{References for Case Study Investigating Morton's MS Rules}

Akçay, Ç., Anderson, R.C., Nowicki, S., Beecher, M.D. \& Searcy, W.A., (2015). Quiet threats: soft song as an aggressive signal in birds. Animal Behaviour, 105, 267-274.

Baker, M. C., (2006), Differentiation of Mating Vocalizations in Birds: Acoustic Features in Mainland and Island Populations and Evidence of Habitat-Dependent Selection on Songs. Ethology, 112, 757-771. 
Beani, L., Dessiv-Fulgheri, F.(1995), Mate choice in the grey partridge, Perdix perdix: role of physical and behavioural male traits. Animal Behaviour, 49, 347-356.

Blaich, C.F. \& Miller, D.B., (1988). Alarm call responsivity of mallard ducklings (Anas platyrhynchos): VI. Effects of sibling and self-produced auditory stimulation. Journal of Comparative Psychology, 102(1), 56.

Bradley, D.W. \& Mennill, D.J., (2009). Strong ungraded responses to playback of solos, duets and choruses in a cooperatively breeding Neotropical songbird. Animal Behaviour, 77(5), 1321-1327.

Benedict, L., Rose, A., Warning, N. (2012). Canyon wrens alter their songs in response to territorial challenges. Animal Behaviour. 84, 1463-1467.

Bretagnolle, V. \& Lequette, B., (1990). Structural variation in the call of the Cory's shearwater (Calonectris diomedea, Aves, Procellariidae). Ethology, 85(4), 313-323.

Burghardt, G. M. (1998). Snake stories: From the additive model to ethology's fifth aim. In L. Hart (Ed.). Responsible conduct of research in animal behavior (pp. 77-95). Oxford, England: Oxford University Press.

Burghardt, G. M. (1999). Deprivation and enrichment in laboratory animal environments. Journal of Applied Animal Welfare Science, 2(4), 263-266.

Burghardt, G. M. (2008). Updating von Uexküll: New directions in communication research. Journal of Comparative Psychology, 122(3), 332.

Burghardt, G. M. (2014). A brief glimpse at the long evolutionary history of play. Animal behavior and cognition, 1(2), 90-98.

Byers, B.E., (2017). Chestnut-sided warblers use rare song types in extreme aggressive Contexts. Animal Behaviour, 125, 33-39.

Cardoso, G.C., Mota, P.G., Depraz, V. (2007). Female and male serins (Serinus serinus) respond differently to derived song traits. Behavioural and Ecological Sociobiology. 61, 1425-1436.

Conover, M.R., (1994). Stimuli eliciting distress calls in adult passerines and response of predators and birds to their broadcast. Behaviour, 131(1), 19-37.

Couchoux, C. \& Dabelsteen, T., (2015). Acoustic cues to individual identity in the rattle calls of common blackbirds: a potential for individual recognition through multisyllabic vocalisations emitted in both territorial and alarm contexts. Behaviour, 152(1), 57-82.

Dabelsteen, T., Mcgregor, P.K., Holland, J. Tobias, J.A., Pedersen, S.B., (1997). The signal function of overlapping singing in male robins. Animal Behaviour. 53, 249 256.

Dakin, R., Montgomerie, R., (2014). Deceptive Copulation Calls Attract Female Visitors to Peacock Leks. The American Naturalist, 183(4), 558-565.

Deregnaucourt, S., Guyomarc'h, J.C., (2003). Mating call discrimination in female European (Coturnix C. coturnix) and Japanese quail (Coturnix C. japonica). Ethology, 109(2), 107-119.

Dubois, A. \& Martens, J., (1984). A case of possible vocal convergence between frogs and a bird in Himalayan torrents. Journal of Ornithology, 125(4), 455-463.

Eda-Fujiwara, H., Satoh, R., Hata, Y., Yamasaki, M., Watanabe, A., Zandbergen, M.A., Okamoto, Y., Miyamoto, T. and Bolhuis, J.J., 2016. Sex differences in behavioural and neural responsiveness to mate calls in a parrot. Scientific reports, 6, doi:https://doi.org/10.1038/srep18481. 
Funghi, C., Cardoso, G. C. \& Mota, P. G., (2015), Increased syllable rate during aggressive singing in a bird with complex and fast song. Journal of Avian Biology, 46, 283-288.

Goodale, E., Kotagama, S.W., (2005). Alarm calling in Sri Lankan mixed-species bird flocks. The Auk, 122(1), 108-120.

Goodale, E., \& Kotagama, S. W. (2006). Vocal mimicry by a passerine bird attracts other species involved in mixed-species flocks. Animal behaviour, 72(2), 471-477.

Goodale, E., \& Kotagama, S. W., (2008). Response to conspecific and heterospecific alarm calls in mixed-species bird flocks of a Sri Lankan rainforest. Behavioral Ecology, 19(4), 887-894.

Griesser, M., (2008). Referential calls signal predator behavior in a group-living bird species. Current Biology, 18(1), 69-73.

Gyger, M., Marler, P. \& Pickert, R., (1987). Semantics of an avian alarm call system: the male domestic fowl, Gallus domesticus. Behaviour, 102(1), 15-39.

Haftorn S. (2000). Contexts and possible functions of alarm calling in the willow tit, Parus montanus; the principle of 'better safe than sorry'. Behaviour. 1, 137(4), 437-49.

Hamao, S., Watanabe, M., Mori, Y., (2011), Urban noise and male density affect songs in the great tit Parus major. Ethology Ecology \& Evolution. 23(2), 111-119.

Kunc, H.P, Amrhein, V. Naguib, M., (2005). Acoustic features of song categories and their possible implications for communication in the common nightingale (Luscinia megarhynchos). Behaviour, 142, 1083-1097.

Klenova, A.V., Zubakin VA, Zubakina EV. (2011). Vocal and optical indicators of individual quality in a social seabird, the crested auklet (Aethia cristatella), Ethology, 117, 356-365.

Lein, M.R., (1980). Display behavior of Ovenbirds (Seiurus aurocapillus) I. Nonsong vocalizations. The Wilson Bulletin, 312-329.

Linhart, P., Jaška, P., Petrusková, T., Petrusek, A. \& Fuchs, R., (2013). Being angry, singing fast? Signalling of aggressive motivation by syllable rate in a songbird with slow song. Behavioural processes, 100, 139-145.

Lowry, H., Lill, A. and Wong, B.B., (2012). How noisy does a noisy miner have to be? Amplitude adjustments of alarm calls in an avian urban 'adapter'. PLoS One, 7(1), e29960.

Magrath, R.D., Pitcher, B.J. \& Gardner, J.L., (2009). Recognition of other species' aerial alarm calls: speaking the same language or learning another? Proceedings of the Royal Society of London B: Biological Sciences, 276(1657), 769-774.

Matessi, G., McGregor, P.K., Peake, T.M. \& Dabelsteen, T., 2005. Do male birds intercept and use rival courtship calls to adjust paternity protection behaviours? $\mathrm{Be}$ haviour, 142(4) 507-524.

Mennill, D.J., \& Ratcliffe, L.M., (2004).Overlapping and matching in the song contests of black-capped chickadees, Animal Behaviour, 67, 441-450.

Mills, D.S., Demontigny-Bédard, I., Gruen, M., Klinck, M.P., McPeake, K.J., Barcelos, A.M., Hewison, L., Van Haevermaet, H., Denenberg, S., Hauser, H. \& Koch, C., 2020. Pain and problem behavior in cats and dogs. Animals, 10(2), 318.

Moran, J. K., Weierstall, R., \& Elbert, T. (2014). Differences in brain circuitry for appetitive and reactive aggression as revealed by realistic auditory scripts. Frontiers in behavioral neuroscience, $8,425$. 
Nowicki, S., Searcy, W.A., (2004). Song function and the evolution of female preferences: why birds sing, why brains matter. Annals of the New York Academy of Sciences, 1016(1), 704-723.

Proppe, D.S. \& Ritchison, G., (2008). Use and possible functions of the primary and sustained songs of male Grasshopper Sparrows. The American Midland Naturalist, 160(1), 1-6.

Rehsteiner, U., Geisser, H., Reyer, H. (1998). Singing and mating success in water pipits: one specific song element makes all the difference. Animal Behaviour. 55, 1471-148.

Riede, T., Forstmeier, W., Kempenaers, B., \& Goller, F. (2015). The functional morphology of male courtship displays in the Pectoral Sandpiper (Calidris melanotos). The Auk: Ornithological Advances, 132(1), 65-77.

Satischandra, S. H. K., Kudavidanage, E. P., Kotagama, S. W., \& Goodale, E. B. E. N. (2007). The benefits of joining mixed-species flocks for greater racket-tailed drongos Dicrurus paradiseus. Forktail, 23, 145.

Schmidt, R., Kunc, H.P., Amrhein, V. \& Naguib, M., (2008). Aggressive responses to broadband trills are related to subsequent pairing success in nightingales. Behavioral Ecology, 19(3) 635-641.

Suzuki, T.N., Wheatcroft, D. \& Griesser, M., (2016). Experimental evidence for compositional syntax in bird calls. Nature Communications, 7.

Tietze, D.T., Martens, J., S, Y-H., Päckert, M., Evolutionary history of treecreeper vocalisations. Organisms Diversity \& Evolution. 8(4), 305-324.

Tinbergen, N. (1963). On aims and methods of ethology. Zeitschrift für tierpsychologie, 20(4), 410-433.

West, M.J., King, A.P. \& Freeberg, T.M., (1998). Dual Signalling during Mating in Brown-headed Cowbirds (Molothrus ater), Family Emberizidae/Icterinae). Ethology, 104(3) 250-267.

Yorzinski, J. L. (2017). The cognitive basis of individual recognition. Current Opinion in Behavioral Sciences, 16, 53-57.

Acknowledgements With acknowledgement to the researcher at Queen's University, Belfast who supervised the short study on Morton's MS rules in 2017. Thanks also to the anonymous reviewers for taking the time to review the article, and for their insightful and thought- provoking comments, which helped me define the novel use of Peircean semiotics and integrate the separate theoretical models.

Open Access This article is licensed under a Creative Commons Attribution 4.0 International License, which permits use, sharing, adaptation, distribution and reproduction in any medium or format, as long as you give appropriate credit to the original author(s) and the source, provide a link to the Creative Commons licence, and indicate if changes were made. The images or other third party material in this article are included in the article's Creative Commons licence, unless indicated otherwise in a credit line to the material. If material is not included in the article's Creative Commons licence and your intended use is not permitted by statutory regulation or exceeds the permitted use, you will need to obtain permission directly from the copyright holder. To view a copy of this licence, visit http://creativecommons.org/licenses/by/4.0/. 


\section{References}

Ainsworth, M. D. S., Bell, S. M., \& Stayton, D. J. (1972). Individual differences in the development of some attachment behaviors. Merrill-Palmer Quarterly of Behavior and Development, 18(2), 123-143.

Arnott, G., \& Elwood, R. W. (2009). Assessment of fighting ability in animal contests. Animal Behaviour, 77(5), 991-1004.

Ashe, A., Vincent C., \& Oldroyd, B.P. (2021). How does epigenetics influence the course of evolution? Philosophical Transactions of the Royal Society B, 37620200111.

Auger-Méthé, M., Derocher, A. E., Plank, M. J., Codling, E. A., \& Lewis, M. A. (2015). Differentiating the Lévy walk from a composite correlated random walk. Methods in Ecology and Evolution, 6(10), 11791189.

Bateson, P., \& Laland, K. N. (2013). Tinbergen 's four questions: An appreciation and an update. Trends in Ecology \& Evolution, 28(12), 712-718.

Beckerman, A. P., Childs, D. Z., \& Petchey, O. L. (2017). Getting started with R: An introduction for biologists. Oxford University Press.

Bird, L. R., Roberts, W. A., Abroms, B., Kit, K. A., \& Crupi, C. (2003). Spatial memory for food hidden by rats (Rattus norvegicus) on the radial maze: Studies of memory for where, what, and when. Journal of Comparative Psychology, 117(2), 176-187.

Booksmythe, I., Jennions, M. D., \& Backwell, P. R. (2010). Investigating the 'dear enemy'phenomenon in the territory defence of the fiddler crab, Uca mjoebergi. Animal Behaviour, 79(2), 419-423.

Burman, O. H., Parker, R. M., Paul, E. S., \& Mendl, M. T. (2009). Anxiety-induced cognitive bias in nonhuman animals. Physiology \& Behavior, 98(3), 345-350.

Burman, O., McGowan, R., Mendl, M., Norling, Y., Paul, E., Rehn, T., \& Keeling, L. (2011). Using judgement bias to measure positive affective state in dogs. Applied Animal Behaviour Science, 132(34), 160-168.

Byrne, R., Fish, J., Doyle, T. K., \& Houghton, J. D. (2009). Tracking leatherback turtles (Dermochelys coriacea) during consecutive inter-nesting intervals: Further support for direct transmitter attachment. Journal of Experimental Marine Biology and Ecology, 377(2), 68-75.

Codling, E. A., Plank, M. J., \& Benhamou, S. (2008). Random walk models in biology. Journal of the Royal Society Interface, 5(25), 813-834.

Cook, P. F., Prichard, A., Spivak, M., \& Berns, G. S. (2016). Awake canine fMRI predicts dogs' preference for praise vs food. Social Cognitive and Affective Neuroscience, 11(12), 1853-1862.

Dale, R., Palma-Jacinto, S., Marshall-Pescini, S., \& Range, F. (2019). Wolves, but not dogs, are prosocial in a touch screen task. PLoS One, 14(5), e0215444.

Dally, J. M., Emery, N. J., \& Clayton, N. S. (2006). Food-caching western scrub-jays keep track of who was watching when. Science, 312(5780), 1662-1665.

Dawkins, M. S. (2007). Observing animal behaviour: Design and analysis of quantitative data. Oxford University Press.

Dasgupta, S., Biswas, A., Abraham, A., \& Das, S. (2008). Adaptive computational chemotaxis in bacterial foraging algorithm. In 2008 International Conference on Complex, Intelligent and Software Intensive Systems (pp. 64-71). IEEE.

De Waal, F. B., Leimgruber, K., \& Greenberg, A. R. (2008). Giving is self-rewarding for monkeys. Proceedings of the National Academy of Sciences, 105(36), 13685-13689.

Dingemanse, N. J., Kazem, A. J., Réale, D., \& Wright, J. (2010). Behavioural reaction norms: Animal personality meets individual plasticity. Trends in Ecology \& Evolution, 25(2), 81-89.

Dyson, S., Berger, J., Ellis, A. D., \& Mullard, J. (2018). Development of an ethogram for a pain scoring system in ridden horses and its application to determine the presence of musculoskeletal pain. Journal of Veterinary Behavior, 23, 47-57.

Dytham, C. (2011). Choosing and using statistics: A biologist 's guide. John Wiley \& Sons.

Emery, N. J., \& Clayton, N. S. (2004). The mentality of crows: Convergent evolution of intelligence in corvids and apes. science, 306(5703), 1903-1907.

Favaro, L., Gamba, M., Cresta, E., Fumagalli, E., Bandoli, F., Pilenga, C., Isaja, V., Mathevon, N., \& Reby, D. (2020). Do penguins' vocal sequences conform to linguistic laws? Biology Letters, 16(2), 20190589.

Fischer, J., Noser, R., \& Hammerschmidt, K. (2013). Bioacoustic field research: A primer to acoustic analyses and playback experiments with primates. American Journal of Primatology, 75(7), 643-663.

Forkman, B., Boissy, A., Meunier-Salaün, M. C., Canali, E., \& Jones, R. B. (2007). A critical review of fear tests used on cattle, pigs, sheep, poultry and horses. Physiology \& Behavior, 92(3), 340-374. 
Gerencsér, L., Bunford, N., Moesta, A., \& Miklósi, Á. (2018). Development and validation of the canine reward responsiveness scale-examining individual differences in reward responsiveness of the domestic dog. Scientific Reports, 8(1), 1-14.

Harding, E. J., Paul, E. S., \& Mendl, M. (2004). Cognitive bias and affective state. Nature, 427(6972), 312312 .

Hall, B. K. (2012). Evolutionary developmental biology (Evo-devo): Past, present, and future. Evolution: Education and Outreach, 5, 184-193.

Hoffmeyer, J. (2011). Biology is immature biosemiotics. In C. Emmeche \& K. Kull (Eds.), Towards a semiotic biology: Life is the action of signs (pp. 43-65). Imperial College Press.

Jaroš, F. (2017). The three semiotic lives of domestic cats: A case study on animal social cognition. Biosemiotics, 10(2), 279-293.

Jaroš, F. (2016). Cats and human societies: A world of interspecific interaction and interpretation. Biosemiotics, 9(2), 287-306.

Jaroš, F., \& Maran, T. (2019). Humans on top, humans among the other animals: Narratives of anthropological difference. Biosemiotics, 12(3), 381-403.

Koolhaas, J. M., Korte, S. M., De Boer, S. F., Van Der Vegt, B. J., Van Reenen, C. G., Hopster, H., De Jong, I. C., Ruis, M. A. W., \& Blokhuis, H. J. (1999). Coping styles in animals: Current status in behavior and stress-physiology. Neuroscience \& Biobehavioral Reviews, 23(7), 925-935.

Kruesi, M. J., Rapoport, J. L., Hamburger, S., Hibbs, E., Potter, W. Z., Lenane, M., \& Brown, G. L. (1990). Cerebrospinal fluid monoamine metabolites, aggression, and impulsivity in disruptive behavior disorders of children and adolescents. Archives of General Psychiatry, 47(5), 419-426.

Kunc, H. P., Amrhein, V., \& Naguib, M. (2006). Vocal interactions in nightingales, Luscinia megarhynchos: More aggressive males have higher pairing success. Animal Behaviour, 72(1), 25-30.

Lehner, P. N. (1987). Design and execution of animal behavior research: An overview. Journal of Animal Science, 65(5), 1213-1219.

Lewis, A. (2020a). Total Umwelten Create Shared Meaning the Emergent Properties of Animal Groups as a Result of Social Signalling. Biosemiotics, 1-11.

Lewis, A. (2020b). Infantilizing Companion Animals through Attachment Theory: Why Shift to Behavioral Ecology-Based Paradigms for Welfare. Society \& Animals, 1(aop), 1-18.

Malassis, R., Rey, A., \& Fagot, J. (2018). Non-adjacent dependencies processing in human and non-human primates. Cognitive Science, 42(5), 1677-1699.

Maran, T. (2017). Mimicry and meaning: Structure and semiotics of biological mimicry (Vol 16). Springer International Publishing.

Martin, P., Bateson, P. P. G., \& Bateson, P. (1993). Measuring behaviour: An introductory guide. Cambridge University Press.

McCafferty, D. J., Moncrieff, J. B., Taylor, I. R., \& Boddie, G. F. (1998). The use of IR thermography to measure the radiative temperature and heat loss of a barn owl (Tyto alba). Journal of Thermal Biology, 23(5), 311-318.

McLoughlin, P. D., Boyce, M. S., Coulson, T., \& Clutton-Brock, T. (2006). Lifetime reproductive success and density-dependent, multi-variable resource selection. Proceedings of the Royal Society B: Biological Sciences, 273(1593), 1449-1454.

McGregor, P. K. (2000). Playback experiments: Design and analysis. Acta ethologica, 3(1), 3-8.

Mendl, M., Burman, O. H., \& Paul, E. S. (2010). An integrative and functional framework for the study of animal emotion and mood. Proceedings of the Royal Society B: Biological Sciences, 277(1696), 28952904.

Mendl, M., Burman, O. H., Parker, R. M., \& Paul, E. S. (2009). Cognitive bias as an indicator of animal emotion and welfare: Emerging evidence and underlying mechanisms. Applied Animal Behaviour Science, 118(3-4), 161-181.

Meisner, G. B. (2018). The Golden ratio: The divine beauty of mathematics. Race Point Publishing.

Myerson, R. B. (1999). Nash equilibrium and the history of economic theory. Journal of Economic Literature, 37(3), 1067-1082.

Naguib, M., \& Mennill, D. J. (2010). The signal value of birdsong: Empirical evidence suggests song overlapping is a signal. Animal Behaviour, 80(3), e11-e15.

Nicol, C. J. (1996). Farm animal cognition. Animal Science, 62(3), 375-391.

Noble, D. (2021). The illusions of the modern synthesis. Biosemiotics, 1-20.

Panksepp, J. (2004). Affective neuroscience: The foundations of human and animal emotions. Oxford University Press. 
Papiorek, S., Junker, R. R., Alves-dos-Santos, I., Melo, G. A., Amaral-Neto, L. P., Sazima, M., Wolowski, M., Freitas, L., \& Lunau, K. (2016). Bees, birds and yellow flowers: Pollinator-dependent convergent evolution of UV patterns. Plant Biology, 18(1), 46-55.

Potter, A., \& Mills, D. S. (2015). Domestic cats (Felis silvestris catus) do not show signs of secure attachment to their owners. PLoS One, 10(9), e0135109.

Sayigh, L. S., Tyack, P. L., Wells, R. S., Solow, A. R., Scott, M. D., \& Irvine, A. B. (1999). Individual recognition in wild bottlenose dolphins: A field test using playback experiments. Animal Behaviour, $57(1), 41-50$.

Smith, J. M. (1979). Game theory and the evolution of behaviour. Proceedings of the Royal Society of London. Series B. Biological Sciences, 205(1161), 475-488.

Wichman, A., Keeling, L. J., \& Forkman, B. (2012). Cognitive bias and anticipatory behaviour of laying hens housed in basic and enriched pens. Applied Animal Behaviour Science, 140(1-2), 62-69.

Ravignani, A. (2018). Spontaneous rhythms in a harbor seal pup calls. BMC Research Notes, 11(1), 1-4.

Salek, M. M., Carrara, F., Fernandez, V., Guasto, J. S., \& Stocker, R. (2019). Bacterial chemotaxis in a microfluidic T-maze reveals strong phenotypic heterogeneity in chemotactic sensitivity. Nature Communications, 10(1), 1-11.

Schmidt, R., Kunc, H. P., Amrhein, V., \& Naguib, M. (2008). Aggressive responses to broadband trills are related to subsequent pairing success in nightingales. Behavioral Ecology, 19(3), 635-641.

Sebeok, T.A., (1990). Essays in Zoosemiotics (monograph series of the Toronto semiotic circle 5). Toronto Semiotic Circle, Victoria College in the University of Toronto.

Shields, S. J., Garner, J. P., \& Mench, J. A. (2004). Dustbathing by broiler chickens: A comparison of preference for four different substrates. Applied Animal Behaviour Science, 87(1-2), 69-82.

Tønnessen, M. (2009). Abstraction, cruelty and other aspects of animal play (exemplified by the playfulness of Muki and Maluca). Sign Systems Studies, 37(3-4), 558-579.

van den Berg, S. M., Heuven, H. C., van den Berg, L., Duffy, D. L., \& Serpell, J. A. (2010). Evaluation of the C-BARQ as a measure of stranger-directed aggression in three common dog breeds. Applied Animal Behaviour Science, 124(3-4), 136-141.

Whiteside, J. H., \& Grice, K. (2016). Biomarker records associated with mass extinction events. Annual Review of Earth and Planetary Sciences, 44, 581-612.

Wright, A. E., Rogers, T. F., Fumagalli, M., Cooney, C. R., \& Mank, J. E. (2019). Phenotypic sexual dimorphism is associated with genomic signatures of resolved sexual conflict. Molecular Ecology, 28(11), 2860-2871.

Yarnell, K., Hall, C., Royle, C., \& Walker, S. L. (2015). Domesticated horses differ in their behavioural and physiological responses to isolated and group housing. Physiology \& Behavior, 143, 51-57.

\section{Websites}

Furtardo, T., King, M., Pinchbeck, G. 2021. The Use of Aletrantive Grazing Systems in the UK, The University of Liverpool. https:/www.liverpool.ac.uk/media/livacuk/equine/documents/ The, use, of,alternative, grazing,systems, in, the,UK.pdf

Publisher's Note Springer Nature remains neutral with regard to jurisdictional claims in published maps and institutional affiliations. 